\title{
Substrate Design Enables Heterobifunctional, Dual "Click" Antibody Modification via Microbial Transglutaminase
}

Joshua A. Walker ${ }^{[a]}$, John J. Bohn ${ }^{[b], \pi}$, Francis Ledesma ${ }^{[a], \pi}$, Michelle R. Sorkin ${ }^{[a]}$, Sneha R. Kabaria $^{[a]}$, Dana N. Thornlow ${ }^{[a]}$, and Christopher A. Alabi[a],*

[a] Robert Frederick Smith School of Chemical and Biomolecular Engineering, Cornell University, 113 Ho Plaza, Ithaca, NY, 14850, United States

[b] Department of Chemical and Biomolecular Engineering, University of Illinois at Urbana-Champaign, $600 \mathrm{~S}$ Mathews Ave, Urbana, IL, 61801, United States

*e-mail: caa238@cornell.edu

\section{Table of Contents}

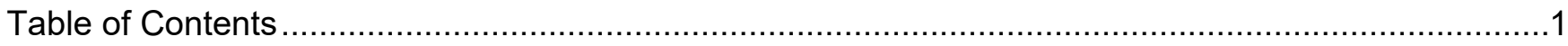

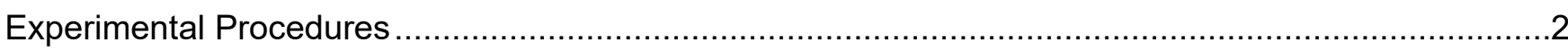

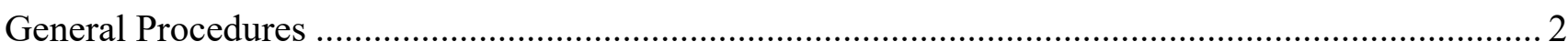

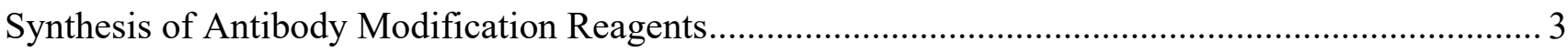

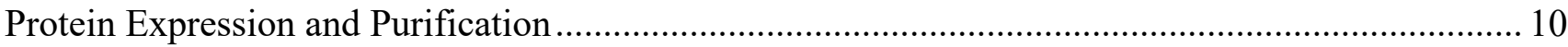

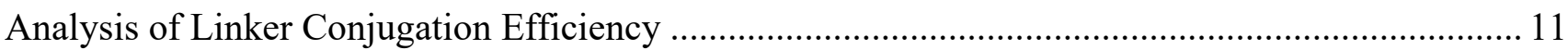

Characterization of Conjugate T5 and Antibody-drug Conjugates............................................... 12

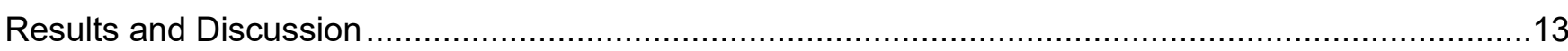

Synthesis of Antibody Modification Reagents....................................................................... 13

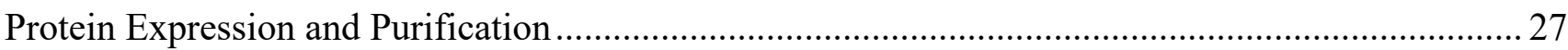

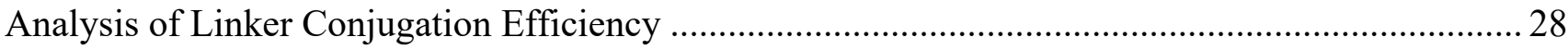

Characterization of Conjugate T5 and Antibody-drug Conjugates...................................................2 29

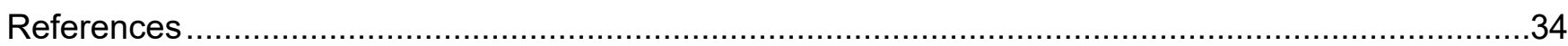




\section{Experimental Procedures}

\section{General Procedures}

\section{Reagents for Chemical Synthesis}

All chemicals were purchased from MilliporeSigma unless stated otherwise. DBCO-PEG4-Amine, (E)cyclooct-4-en-1-yl (3-aminopropyl)carbamate (TCO-Amine), DM1, mTz-NHS ester, mTz-PEG5-NHS ester, and tert-butyl (2-(2-(2-bromoethoxy)ethoxy)ethyl) carbamate were purchased from BroadPharm. Azidopropan-1-amine was purchased from Click Chemistry Tools. OPSS-PEG24-NHS ester and mPEG24-NHS ester were purchased from Quanta Biodesign. PEG5K-SVA was purchased from Laysan Bio. DM1-S-Me was purchased from Toronto Research Chemicals.

\section{Reagents for Protein Expression and Purification}

The plasmid pDJ1-3 was kindly provided by Professor Joelle Pelletier (Université de Montréal, Montreal, Canada). pDJ1-3 encodes the proenzyme of microbial transglutaminase from $S$. mobaraensis with its $\mathrm{N}$-terminal pro-sequence and a C-terminal hexa-histidine tag inserted between the Ndel and Xhol restriction sites of the vector pET20b. The plasmid pVITRO-Trastuzumab-lgG1/k for expressing trastuzumab was purchased from Addgene (Plasmid\# 61883). Ni-NTA agarose resin was purchased from Qiagen. NAb protein $A / G$ resin was purchased from ThermoFisher Scientific. Sequencing primers (T7 forward and reverse) were purchased from Integrated DNA Technologies (IDT). Sequencing was performed at the Cornell University Genomics Facility using the Applied Biosystems Automated 370xI DNA Analyzer using Big Dye Terminator chemistry and ApliTag-FS DNA Polymerase.

\section{Reagents for Gel Electrophoresis, Molecular Biology, and Cell Culture}

Sulfo-Cy5 TCO was purchased from BroadPharm. DBCO-PEG4-Carboxyrhodamine 101 was purchased from Click Chemistry Tools. Precast protein gels (4 - 20\% mini-PROTEAN ${ }^{2}$ TGX ${ }^{\mathrm{TM}}$ ) and Bio-safe Coomassie Stain were purchased from Bio-Rad Laboratories. Peptide:N-glycosidase F (PNGase F) was purchased from New England Biolabs. All cell culture reagents were purchased from ThermoFisher Scientific unless stated otherwise. HEK293F cells were cultured in FreeStyle ${ }^{\mathrm{TM}} 293$ Expression Medium. SKOV3 and MCF7 cells were cultured in Dulbecco's Modified Eagle Medium (DMEM) and DMEM supplemented with insulin $(0.01 \mathrm{mg} / \mathrm{mL})$, respectively. CellTiter $96 \AA A Q_{\text {ueous }}$ One Solution Cell Proliferation Assay (MTS) was purchased from Promega.

\section{Nuclear Magnetic Resonance (NMR) Spectroscopy}

${ }^{1} \mathrm{H}$ and ${ }^{13} \mathrm{C}$ NMR spectra were recorded on either an INOVA $400 \mathrm{MHz}$ or $500 \mathrm{MHz}$ spectrometer as specified. NMR data was analyzed by MestReNova software. ${ }^{1} \mathrm{H}$ and ${ }^{13} \mathrm{C}$ NMR chemical shifts are reported in units of ppm relative to chloroform.

\section{Liquid Chromatography Mass Spectrometry (LC-MS)}

LC-MS analysis was carried out on an Agilent 1100 Series LC with a Poroshell 120 EC-C18 column (100 $\times 3 \mathrm{~mm}, 2.7 \mu \mathrm{m}$, Agilent Technologies) and an Agilent G1956B Series Single Quadripole MS in positive ion mode for mass detection. The mobile phase for LC-MS (solvent $A$ ) was water with $0.1 \%(v / v)$ acetic acid, and the stationary phase (solvent $B$ ) was acetonitrile with $0.1 \%(\mathrm{v} / \mathrm{v})$ acetic acid. Compounds were eluted at a flow rate of $0.6 \mathrm{~mL} / \mathrm{min}$ using a gradient of $5-100 \%$ solvent $\mathrm{B}(0-10$ minutes $)$ followed by $100 \%$ solvent $B(10-12$ minutes) and equilibrated back to $5 \%$ solvent $B$ (12-15 minutes).

\section{Reverse Phase High Performance Liquid Chromatography (RP-HPLC) Purification}

HPLC purification was performed on an Agilent 1100 Series HPLC system equipped with a UV diode array detector and an 1100 Infinity fraction collector using a semi-preparative reversed-phase $\mathrm{C} 18$ column (Agilent Eclipse XDB-C18, $9.4 \times 250 \mathrm{~mm}, 5 \mu \mathrm{m}$ ). The mobile phase for HPLC was water with $0.1 \%(\mathrm{v} / \mathrm{v})$ trifluoroacetic acid (solvent $\mathrm{A}$ ) and acetonitrile with $0.1 \%(\mathrm{v} / \mathrm{v})$ trifluoroacetic acid (solvent $\mathrm{B}$ ) unless specified otherwise. Compounds were eluted at a flow rate of $4 \mathrm{~mL} / \mathrm{min}$ using a linear solvent gradient as specified below. 


\section{Hydrophobic Interaction Chromatography (HIC)}

HIC was performed on an Agilent 1100 Series HPLC system equipped with a UV diode array detector and an 1100 Infinity fraction collector using a reversed-phase phenyl column (Tosoh Biosciences LLC, TSKgel Phenyl-5PW, $7.5 \times 75 \mathrm{~mm}, 10 \mu \mathrm{m})$. The mobile phase for HIC was $25 \mathrm{mM}$ phosphate, $1.5 \mathrm{M}$ ammonium sulfate, $\mathrm{pH} 7.0$ (solvent $\mathrm{A}$ ) and $18.75 \mathrm{mM}$ phosphate, $25 \%(\mathrm{v} / \mathrm{v}$ ) isopropyl alcohol, $\mathrm{pH} 7.0$ (solvent B). Compounds were eluted at a flow rate of $1 \mathrm{~mL} / \mathrm{min}$ using a linear solvent gradient as specified below.

\section{Gel Electrophoresis of Conjugates}

All samples were denatured and reduced with 2-mercaptoethanol by boiling at $100{ }^{\circ} \mathrm{C}$ for 5 minutes. A precast $4-20 \%$ mini-PROTEAN® TGX ${ }^{\mathrm{TM}}$ gel was run for 60 minutes at $120 \mathrm{~V}$ to separate the protein samples. Protein content was visualized using Bio-Safe Coomassie Stain according to the

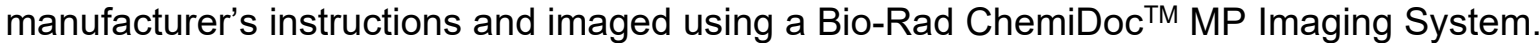

\section{Synthesis of Antibody Modification Reagents}

\section{Synthesis of Linker 1 (Compound 3)}<smiles>CCN(CC)CCC(C)(C)OC(=O)NCCNCCCN</smiles>

(1)<smiles>CCN(CC)CC(C)(C)C(C)(C)C(=O)NCCN(CCCN)C(=O)Cc1ccc(-c2nnc(C)nn2)cc1</smiles><smiles>Cc1nnc(-c2ccc(CC(=O)N(CCCN)CCCN)cc2)nn1</smiles>

Supplementary Figure S1. Synthesis scheme for Linker 1.

Synthesis of (1): 1 equivalency (20 mg, $92 \mu \mathrm{mol}$ ) of tert-butyl (2-bromoethyl)carbamate was dissolved at $400 \mathrm{mM}$ in dimethyl sulfoxide (solution 1). 2 equivalencies of azidopropan-1-amine and 2 equivalencies of triethylamine were dissolved at $400 \mathrm{mM}$ in dimethyl sulfoxide (solution 2). Solution 1 was added dropwise to solution 2 at room temperature over 2 hours. The resulting mixture was reacted at room temperature overnight and then purified via semi-preparative RP-HPLC. The reaction mixture was separated using a linear solvent gradient of $5-45 \%$ solvent B over 20 minutes. The product (1) eluted at 11.5 minutes and was recovered in $94 \%$ yield $(21 \mathrm{mg}, 87 \mu \mathrm{mol})$. The product was characterized by LC-MS ((1) calculated: 244.17 , observed: $\left.244.20[\mathrm{M}+\mathrm{H}]^{+}\right)$. 
Synthesis of (2): 1 equivalency (10.5 mg, $43 \mu \mathrm{mol}$ ) of (1) was dissolved at $300 \mathrm{mM}$ in dimethyl sulfoxide in the presence of 5 equivalencies of triethylamine. To this solution, 1 equivalency of $\mathrm{mTz}$-NHS ester dissolved at $300 \mathrm{mM}$ in dimethylsulfoxide was added. The resulting mixture was reacted at room temperature overnight and then purified via semi-preparative RP-HPLC. The reaction mixture was separated using a linear solvent gradient of $5-95 \%$ solvent B over 30 minutes. The product (2) eluted at 22 minutes and was recovered in $60 \%$ yield $(11.7 \mathrm{mg}, 26 \mu \mathrm{mol})$. The product was characterized by ${ }^{1} \mathrm{H}$ NMR (Figure S11) and LC-MS ((2) calculated: 478.24, observed: $\left.478.00[\mathrm{M}+\mathrm{Na}]^{+}\right)$.

Synthesis of (3): Removal of the BOC protecting group was achieved by dissolving (2) at $5 \mathrm{mM}$ in $50 \%$ $(\mathrm{v} / \mathrm{v})$ trifluoroacetic acid in dichloromethane at room temperature for 1 hour. The solvent was then removed under vacuum, and the product was purified via semi-preparative RP-HPLC. The dried product was separated using a linear solvent gradient of $5-50 \%$ solvent B over 22.5 minutes. The product (3) eluted at 14.5 minutes and was recovered in $94 \%$ yield $(8.6 \mathrm{mg}, 24 \mu \mathrm{mol})$. The product was characterized by ${ }^{1} \mathrm{H}$ NMR (Figure S12) and LC-MS ((3) calculated: 356.19, observed: $356.10[\mathrm{M}+\mathrm{H}]^{+}$).

\section{Synthesis of 1-azido-2-(2-(2-bromoethoxy)ethoxy)ethane (Compound 6)}<smiles>CCN(CC)CC[C@H](C)C(=O)O</smiles><smiles>Cc1ccc(S(=O)(=O)OCCOCCOCCO)cc1</smiles><smiles>NCCOCCOCCBr</smiles>

(5)

(6)

Supplementary Figure S2. Synthesis scheme for 1-azido-2-(2-(2-bromoethoxy)ethoxy)ethane.

Synthesis of (4): 1 equivalency of 4-methylbenzenesulfonyl chloride $(3.5 \mathrm{~g}, 18.4 \mathrm{mmol})$ was dissolved at $175 \mathrm{mM}$ in dichloromethane. Separately, 4 equivalencies of 2,2'-(ethane-1,2-diylbis(oxy))bis(ethan-1-ol) $(11 \mathrm{~g}, 73 \mathrm{mmol})$ was dissolved at $110 \mathrm{mM}$ in dichloromethane. To this solution was added 1.05 equivalencies of triethylamine $(1.95 \mathrm{~g}, 19 \mathrm{mmol})$ and 0.02 equivalencies of 4-dimethylaminopyridine (46 $\mathrm{mg}, 0.3 \mathrm{mmol}$ ), and the mixture was allowed to equilibrate for 10 minutes on ice. The solution of 4methylbenzenesulfonyl chloride in DCM was then added dropwise to the mixture over 2 hours. The mixture was subsequently removed from the ice and reacted at room temperature overnight. The reaction was quenched with $100 \mathrm{~mL}$ of water and extracted with dichloromethane $(100 \mathrm{~mL}, 3 \mathrm{x})$. The organic layer was collected, dried with sodium sulfate, and concentrated under vacuum. The crude product (4), recovered in $98 \%$ yield $(5.5 \mathrm{~g}, 18 \mathrm{mmol})$, was used without further purification. The product was characterized by ${ }^{1} \mathrm{H}$ and ${ }^{13} \mathrm{C}$ NMR (Figures S13 and S14).

Synthesis of (5): 1 equivalency $(4.8 \mathrm{~g}, 16 \mathrm{mmol})$ of (4) was dissolved at $739 \mathrm{mM}$ in dry dimethylformamide (DMF). To this solution was added 2 equivalencies of sodium azide $(2 \mathrm{~g}, 32 \mathrm{mmol})$ and the mixture was reacted overnight at $80^{\circ} \mathrm{C}$. The mixture was then concentrated under vacuum. The residue was suspended in diethyl ether and filtered through celite. The filtered product was collected and concentrated under vacuum. The crude product (5), recovered in $96 \%$ yield $(2.7 \mathrm{~g}, 15.4 \mathrm{mmol})$, was used without further purification. The product was characterized by ${ }^{1} \mathrm{H}$ NMR (Figure S15). 
Synthesis of (6): 1 equivalency ( $1 \mathrm{~g}, 5.8 \mathrm{mmol}$ ) of (5) was dissolved at $342 \mathrm{mM}$ in dry chloroform. To this solution was added 2 equivalencies of phosphorus tribromide $(3.1 \mathrm{~g}, 12 \mathrm{mmol})$ over 5 minutes. The mixture was refluxed overnight at $50^{\circ} \mathrm{C}$. The reaction was quenched on ice over 30 minutes with $75 \mathrm{~mL}$ of saturated sodium bicarbonate solution and extracted with chloroform (100 mL, 3x). The organic layer was collected, dried with sodium sulfate, and concentrated under vacuum. The crude product (6), recovered in $30 \%$ yield $(0.4 \mathrm{~g}, 1.7 \mathrm{mmol})$, was used without further purification. The product was characterized by ${ }^{1} \mathrm{H}$ and ${ }^{13} \mathrm{C}$ NMR (Figures S16 and S17).

\section{Synthesis of Linker 2 (Compound 9)}

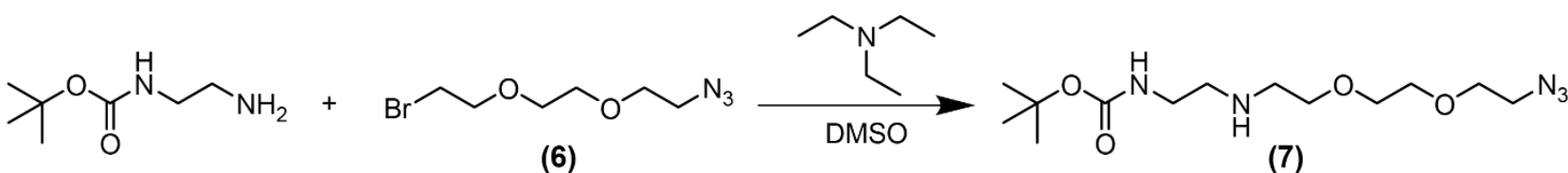

(6)<smiles>Cc1nnc(-c2ccc(CC(=O)ON3C(=O)CCC3=O)cc2)nn1</smiles><smiles>CCN(CC)CC(C)C(C)(C)OC(=O)NCCN(CCOCCOCCN)C(=O)Cc1ccc(-c2nnc(C)nn2)cc1</smiles>

(8)<smiles>Cc1nnc(-c2ccc(CC(=O)N(CCN)CCOCCOCC[18O])cc2)nn1</smiles>

Supplementary Figure S3. Synthesis scheme for Linker 2.

Synthesis of (7): 1 equivalency (38 mg, $159 \mu \mathrm{mol}$ ) of (6) was dissolved at $400 \mathrm{mM}$ in dimethyl sulfoxide (solution 1). 2 equivalencies of tert-butyl (2-aminoethyl)carbamate and 2 equivalencies of triethylamine were dissolved at $400 \mathrm{mM}$ in dimethyl sulfoxide (solution 2). Solution 1 was added dropwise to solution 2 at room temperature over 2 hours. The resulting mixture was reacted at room temperature overnight and then purified via semi-preparative RP-HPLC. The reaction mixture was separated using a linear solvent gradient of $5-45 \%$ solvent B over 20 minutes. The product (7) eluted at 13.5 minutes and was recovered in $52 \%$ yield $(26 \mathrm{mg}, 83 \mu \mathrm{mol})$. The product was characterized by LC-MS $(\mathbf{( 7 )}$ calculated: 318.21, observed: $318.20[\mathrm{M}+\mathrm{H}]^{+}$). 
Synthesis of (8): 1 equivalency (6.6 mg, $21 \mu \mathrm{mol}$ ) of (7) was dissolved at $300 \mathrm{mM}$ in dimethyl sulfoxide in the presence of 5 equivalencies of triethylamine. To this solution, 1 equivalency of mTz-NHS ester dissolved at $300 \mathrm{mM}$ in dimethylsulfoxide was added. The resulting mixture was reacted at room temperature overnight and then purified via semi-preparative RP-HPLC. The reaction mixture was separated using a linear solvent gradient of $5-95 \%$ solvent B over 30 minutes. The product (8) eluted at 21 minutes and was recovered in $28 \%$ yield $(3.1 \mathrm{mg}, 6 \mu \mathrm{mol})$. The product was characterized by ${ }^{1} \mathrm{H}$ NMR (Figure S18) and LC-MS ((8) calculated: 552.28, observed: $\left.552.10[\mathrm{M}+\mathrm{Na}]^{+}\right)$.

Synthesis of (9): Removal of the BOC protecting group was achieved by dissolving (8) at $5 \mathrm{mM}$ in $50 \%$ $(\mathrm{v} / \mathrm{v})$ trifluoroacetic acid in dichloromethane at room temperature for 1 hour. The solvent was then removed under vacuum, and the product was purified via semi-preparative RP-HPLC. The dried product was separated using a linear solvent gradient of $5-50 \%$ solvent B over 22.5 minutes. The product (8) eluted at 16 minutes and was recovered in $85 \%$ yield $(2.6 \mathrm{mg}, 6 \mu \mathrm{mol})$. The product was characterized by ${ }^{1} \mathrm{H}$ NMR (Figure S19) and LC-MS ((9) calculated: 430.22, observed: $\left.430.10[\mathrm{M}+\mathrm{H}]^{+}\right)$.

\section{Synthesis of Linker 3 (Compound 11)}<smiles>CCN(CC)CC(C)(C)C</smiles><smiles>Cc1nnc(-c2ccc(OCCC(=O)N(CCCN)CCCN)cc2)nn1</smiles>

Supplementary Figure S4. Synthesis scheme for Linker 3.

Synthesis of (10): 1 equivalency (10.5 mg, $43 \mu \mathrm{mol}$ ) of (1) was dissolved at $300 \mathrm{mM}$ in dimethyl sulfoxide in the presence of 5 equivalencies of triethylamine. To this solution, 0.36 equivalencies of mTz-PEG5NHS ester dissolved at $300 \mathrm{mM}$ in dimethylsulfoxide was added. The resulting mixture was reacted at room temperature overnight and then purified via semi-preparative RP-HPLC. The reaction mixture was separated using a linear solvent gradient of $5-95 \%$ solvent B over 30 minutes. The product (10) eluted at 22.5 minutes and was recovered in $74 \%$ yield $(7.6 \mathrm{mg}, 11.5 \mu \mathrm{mol})$. The product was characterized by ${ }^{1} \mathrm{H}$ NMR (Figure S20) and LC-MS ((10) calculated: 684.35, observed: $\left.684.10[\mathrm{M}+\mathrm{Na}]^{+}\right)$.

Synthesis of (11): Removal of the BOC protecting group was achieved by dissolving (10) at $5 \mathrm{mM}$ in $50 \%$ $(\mathrm{v} / \mathrm{v})$ trifluoroacetic acid in dichloromethane at room temperature for 1 hour. The solvent was then removed under vacuum, and the product was purified via semi-preparative RP-HPLC. The dried product was separated using a linear solvent gradient of $5-50 \%$ solvent B over 22.5 minutes. The product (3) eluted at 18.5 minutes and was recovered in $79 \%$ yield $(5.1 \mathrm{mg}, 9 \mu \mathrm{mol})$. The product was characterized by ${ }^{1} \mathrm{H}$ NMR (Figure S21) and LC-MS ((11) calculated: 562.30, observed: $\left.562.20[\mathrm{M}+\mathrm{H}]^{+}\right)$. 


\section{Synthesis of Linker 4 (Compound 14)}<smiles>CCN(CC)CCC(C)(C)OC(=O)NCCOCCOCCNCCCN</smiles><smiles>CCN(CC)CC(C)(C)C(C)(C)C(=O)NCCOCCOCCN(CCCN)C(=O)Cc1ccc(-c2nnc(C)nn2)cc1</smiles><smiles>Cc1nnc(-c2ccc(CC(=O)N(CCCN)CCOCCOCCN)cc2)nn1</smiles>

Supplementary Figure S5. Synthesis scheme for Linker 4.

Synthesis of (12): 1 equivalency ( $24.6 \mathrm{mg}, 79 \mu \mathrm{mol})$ of tert-butyl (2-(2-(2-bromoethoxy)ethoxy)ethyl) carbamate was dissolved at $400 \mathrm{mM}$ in dimethyl sulfoxide (solution 1). 2 equivalencies of azidopropan1-amine and 2 equivalencies of triethylamine were dissolved at $400 \mathrm{mM}$ in dimethyl sulfoxide (solution 2). Solution 1 was added dropwise to solution 2 at room temperature over 2 hours. The resulting mixture was reacted at room temperature overnight and then purified via semi-preparative RP-HPLC. The reaction mixture was separated using a linear solvent gradient of $5-45 \%$ solvent B over 20 minutes. The product (12) eluted at 13.5 minutes and was recovered in $75 \%$ yield $(19.6 \mathrm{mg}, 59 \mu \mathrm{mol})$. The product was characterized by LC-MS ((12) calculated: 332.22 , observed: $\left.332.20[\mathrm{M}+\mathrm{H}]^{+}\right)$.

Synthesis of (13): 1 equivalency (7.4 mg, $22 \mu \mathrm{mol}$ ) of (12) was dissolved at $300 \mathrm{mM}$ in dimethyl sulfoxide in the presence of 5 equivalencies of triethylamine. To this solution, 1 equivalency of mTz-NHS ester dissolved at $300 \mathrm{mM}$ in dimethylsulfoxide was added. The resulting mixture was reacted at room temperature overnight and then purified via semi-preparative RP-HPLC. The reaction mixture was separated using a linear solvent gradient of $5-95 \%$ solvent B over 30 minutes. The product (13) eluted at 21 minutes and was recovered in $27 \%$ yield $(3.3 \mathrm{mg}, 6.1 \mu \mathrm{mol})$. The product was characterized by ${ }^{1} \mathrm{H}$ NMR (Figure S22) and LC-MS ((13) calculated: 566.29, observed: $\left.566.10[\mathrm{M}+\mathrm{Na}]^{+}\right)$.

Synthesis of (14): Removal of the BOC protecting group was achieved by dissolving (13) at $5 \mathrm{mM}$ in $50 \%$ $(\mathrm{v} / \mathrm{v})$ trifluoroacetic acid in dichloromethane at room temperature for 1 hour. The solvent was then removed under vacuum, and the product was purified via semi-preparative RP-HPLC. The dried product was separated using a linear solvent gradient of $5-50 \%$ solvent B over 22.5 minutes. The product (14) eluted at 16.5 minutes and was recovered in $92 \%$ yield $(2.5 \mathrm{mg}, 5.6 \mu \mathrm{mol})$. The product was characterized by ${ }^{1} \mathrm{H}$ NMR (Figure S23) and LC-MS ((3) calculated: 444.24 , observed: $444.10[\mathrm{M}+\mathrm{H}]^{+}$). 


\section{Synthesis of Linker 5 (Compound 17)}<smiles>CCN(CC)CCC(C)(C)OC(=O)NCCOCCOCCNCCOCCOCCN</smiles><smiles>CCN(CC)CC(C)(C)C</smiles><smiles>Cc1nnc(-c2ccc(CC(=O)N(CCOCCOCCN)CCOCCOCCN(CCOCCOCCNC(=O)OC(C)(C)C)C(=O)Cc3ccc(-c4nnc(C)nn4)cc3)cc2)nn1</smiles>

Supplementary Figure S6. Synthesis scheme for Linker 5.

Synthesis of (15): 1 equivalency (38 mg, $159 \mu \mathrm{mol}$ ) of (6) was dissolved at $400 \mathrm{mM}$ in dimethyl sulfoxide (solution 1). 2 equivalencies of tert-butyl (2-(2-(2-aminoethoxy)ethoxy)ethyl)carbamate and 2 equivalencies of triethylamine were dissolved at $400 \mathrm{mM}$ in dimethyl sulfoxide (solution 2). Solution 1 was added dropwise to solution 2 at room temperature over 2 hours. The resulting mixture was reacted at room temperature overnight and then purified via semi-preparative RP-HPLC. The reaction mixture was separated using a linear solvent gradient of $5-45 \%$ solvent B over 20 minutes. The product (15) eluted at 15.5 minutes and was recovered in $26 \%$ yield $(17 \mathrm{mg}, 42 \mu \mathrm{mol})$. The product was characterized by LC-MS ((15) calculated: 406.25 , observed: $\left.406.10[\mathrm{M}+\mathrm{H}]^{+}\right)$.

Synthesis of (16): 1 equivalency (8.6 mg, $21 \mu \mathrm{mol}$ ) of (15) was dissolved at $300 \mathrm{mM}$ in dimethyl sulfoxide in the presence of 5 equivalencies of triethylamine. To this solution, 1 equivalency of $\mathrm{mTz}$-NHS ester dissolved at $300 \mathrm{mM}$ in dimethylsulfoxide was added. The resulting mixture was reacted at room temperature overnight and then purified via semi-preparative RP-HPLC. The reaction mixture was separated using a linear solvent gradient of $5-95 \%$ solvent B over 30 minutes. The product (16) eluted at 20.5 minutes and was recovered in $51 \%$ yield $(6.7 \mathrm{mg}, 11 \mu \mathrm{mol})$. The product was characterized by ${ }^{1} \mathrm{H}$ NMR (Figure S24) and LC-MS ((8) calculated: 640.33, observed: $\left.640.10[\mathrm{M}+\mathrm{Na}]^{+}\right)$.

Synthesis of (17): Removal of the BOC protecting group was achieved by dissolving (16) at $5 \mathrm{mM}$ in $50 \%$ $(\mathrm{v} / \mathrm{v})$ trifluoroacetic acid in dichloromethane at room temperature for 1 hour. The solvent was then removed under vacuum, and the product was purified via semi-preparative RP-HPLC. The dried product was separated using a linear solvent gradient of $5-50 \%$ solvent B over 22.5 minutes. The product (17) eluted at 17.5 minutes and was recovered in $91 \%$ yield $(5.1 \mathrm{mg}, 10 \mu \mathrm{mol})$. The product was characterized by ${ }^{1} \mathrm{H}$ NMR (Figure S25) and LC-MS ((9) calculated: 518.28, observed: $518.20[\mathrm{M}+\mathrm{H}]^{+}$). 


\section{Synthesis of DBCO-PEG5K (Compound 18)}

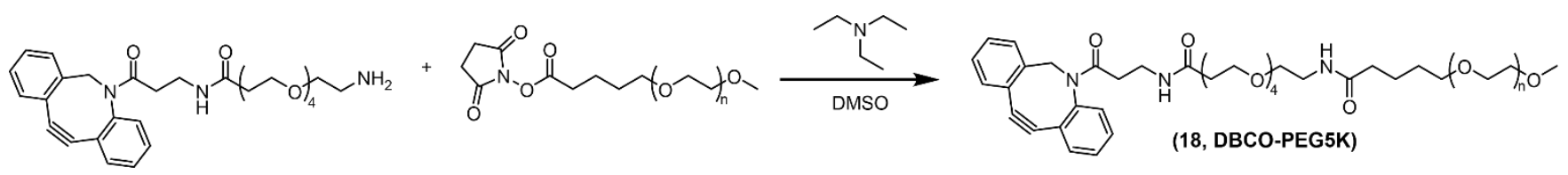

Supplementary Figure S7. Synthesis scheme for DBCO-PEG5K.

1 equivalency $(1.7 \mathrm{mg}, 3.2 \mu \mathrm{mol})$ of DBCO-PEG4-Amine was dissolved at $100 \mathrm{mM}$ in dimethyl sulfoxide in the presence of 5 equivalencies of triethylamine. To this solution, 1.25 equivalencies of PEG5K-SVA dissolved at $50 \mathrm{mM}$ in dimethylsulfoxide was added. The resulting mixture was reacted at room temperature overnight and then purified via semi-preparative RP-HPLC. The reaction mixture was separated using a mobile phase of water (solvent A) and acetonitrile (solvent B) and a linear solvent gradient of $5-65 \%$ solvent $B$ over 30 minutes. The product (18) eluted at 25 minutes and was recovered in $62 \%$ yield $(10 \mathrm{mg}, 1.8 \mu \mathrm{mol})$. The product was characterized by MALDI-MS (Figure S26).

\section{Synthesis of TCO-PEG5K (Compound 19)}<smiles>NCCCNC(=O)OC1CCC=CCC1</smiles><smiles>CCN(CC)CCCCOC(C)(C)CCC(C)OC</smiles><smiles>CO[C@H](C)OCCCCCC(=O)NCCCNC(=O)OC1CC/C=C\CCC1</smiles>

Supplementary Figure S8. Synthesis scheme for TCO-PEG5K.

1 equivalency $(0.7 \mathrm{mg}, 3.2 \mu \mathrm{mol})$ of TCO-Amine was dissolved at $100 \mathrm{mM}$ in dimethyl sulfoxide in the presence of 5 equivalencies of triethylamine. To this solution, 1.25 equivalencies of PEG5K-SVA dissolved at $50 \mathrm{mM}$ in dimethylsulfoxide was added. The resulting mixture was reacted at room temperature overnight and then purified via semi-preparative RP-HPLC. The reaction mixture was separated using a mobile phase of water (solvent $A$ ) and acetonitrile (solvent $B$ ) and a linear solvent gradient of $5-65 \%$ solvent B over 30 minutes. The product (19) eluted at 24.5 minutes and was recovered in $80 \%$ yield $(12.8 \mathrm{mg}, 2.5 \mu \mathrm{mol})$. The product was characterized by MALDI-MS (Figure S27).

\section{Synthesis of DBCO-PEG28 (Compound 20)}

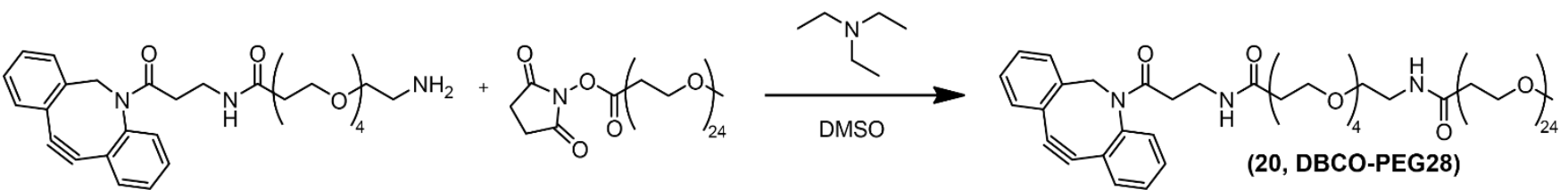

Supplementary Figure S9. Synthesis scheme for DBCO-PEG28.

1 equivalency (2 mg, $3.8 \mu \mathrm{mol}$ ) of DBCO-PEG4-Amine was dissolved at $190 \mathrm{mM}$ in dimethyl sulfoxide in the presence of 5 equivalencies of triethylamine. To this solution, 1 equivalency of mPEG24-NHS ester dissolved at $100 \mathrm{mM}$ in dimethylsulfoxide was added. The resulting mixture was reacted at room temperature overnight and then purified via semi-preparative RP-HPLC. The reaction mixture was separated using a linear solvent gradient of $5-95 \%$ solvent B over 45 minutes. The product (20) eluted at 24.5 minutes and was recovered in $47 \%$ yield $(2.9 \mathrm{mg}, 1.8 \mu \mathrm{mol})$. The product was characterized by LC-MS ((20) calculated: 1622.91, observed: $\left.1622.60[\mathrm{M}+\mathrm{H}]^{+}\right)$. 


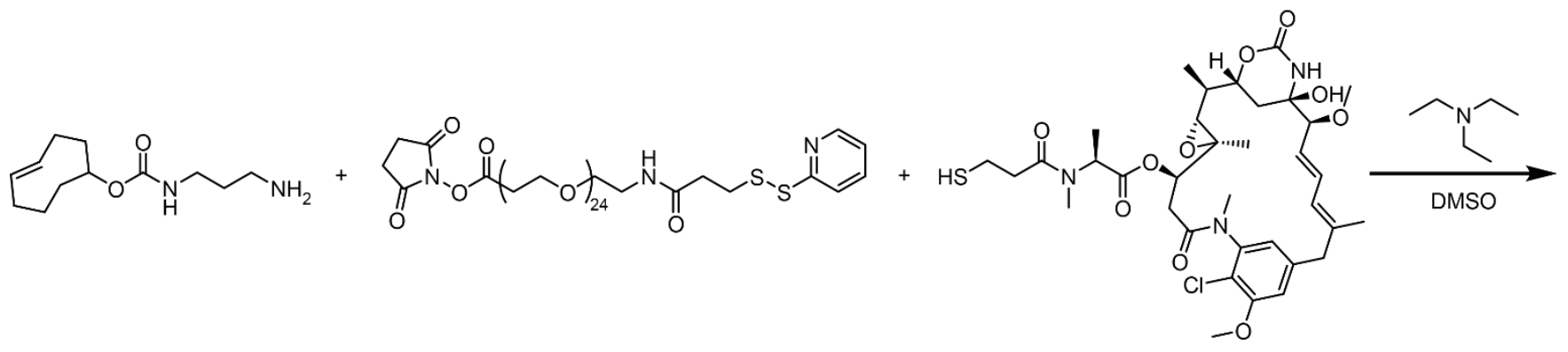

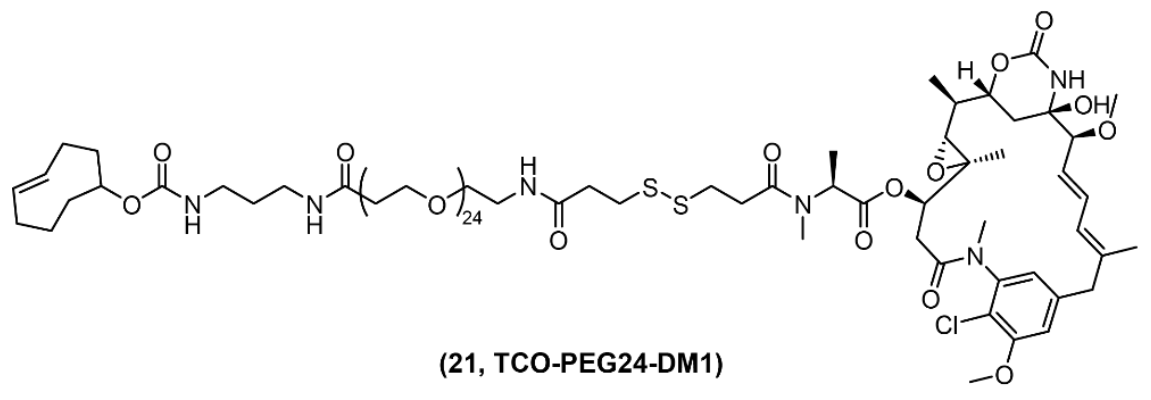

Supplementary Figure S10. Synthesis scheme for TCO-PEG24-DM1.

1 equivalency $(2.6 \mathrm{mg}, 9.9 \mu \mathrm{mol}$ ) of TCO-Amine was dissolved at $100 \mathrm{mM}$ in dimethyl sulfoxide in the presence of 5 equivalencies of triethylamine. To this solution, 0.67 equivalencies of OPSS-PEG24-NHS ester dissolved at $100 \mathrm{mM}$ in dimethyl sulfoxide was added. The resulting mixture was reacted at room temperature for 1 hour. To this solution, 0.67 equivalencies of DM1 dissolved at $100 \mathrm{mM}$ in dimethyl sulfoxide was added. The resulting mixture was reacted at room temperature for 4 hours and then purified via semi-preparative RP-HPLC. The reaction mixture was separated using a linear solvent gradient of $5-75 \%$ solvent B over 35 minutes. The product (21) eluted at 27 minutes and was recovered in $76 \%$ yield $(10.9 \mathrm{mg}, 5 \mu \mathrm{mol})$. The product was characterized by LC-MS. Details of the characteristic LC-MS fragmentation pattern are given in (Figure S28).

\section{Protein Expression and Purification}

\section{Expression and Purification of Microbial Transglutaminase}

Microbial transglutaminase (MTG) was expressed and purified as previously described with minor modifications. ${ }^{1}$ Briefly, plasmid pDJ1-3 was transformed into E. coli BL21 (DE3), using standard procedures, and maintained with $100 \mu \mathrm{g} / \mathrm{mL}$ ampicillin. Before protein expression, correct plasmid sequence was confirmed (Table S1). A $5 \mathrm{~mL}$ starter culture was propagated overnight at $37^{\circ} \mathrm{C}$ with shaking at $240 \mathrm{rpm}$ in ZYP-0.8G media. The starter culture $(2.5 \mathrm{~mL})$ was used to inoculate $250 \mathrm{~mL}$ of auto-inducing ZYP-5052 medium. The expression culture was grown for 2 hours at $37^{\circ} \mathrm{C}$ with shaking at $240 \mathrm{rpm}$. After 2 hours, the temperature was reduced to $22^{\circ} \mathrm{C}$ for 20 hours. Cells were collected by centrifugation at $3,000 \mathrm{xg}$ at $4^{\circ} \mathrm{C}$ for 30 minutes. The cell pellet was suspended in $8 \mathrm{~mL}$ of $0.2 \mathrm{M} \mathrm{Tris}-\mathrm{HCl}$, $\mathrm{pH}$ 6.0. The cells were disrupted by sonication at $4^{\circ} \mathrm{C}$ (Qsonica Model CL-18, 3 cycles of 30 second pulse at $20 \%$ intensity with 60 second pause). The $\mathrm{N}$-terminal MTG pro-sequence was removed by treatment for 45 minutes at $30^{\circ} \mathrm{C}$ with $800 \mu \mathrm{L}$ of trypsin at a concentration of $1 \mathrm{mg} / \mathrm{mL}$ in $0.2 \mathrm{M} \mathrm{Tris}-\mathrm{HCl}$, $\mathrm{pH}$ 6.0. Activated MTG was purified using a gravity flow column charged with $0.5 \mathrm{~mL}$ of Ni-NTA resin. The column was equilibrated in a buffer of $50 \mathrm{mM}$ phosphate, $300 \mathrm{mM} \mathrm{NaCl}$, and $2 \mathrm{mM}$ reduced glutathione, $\mathrm{pH}$ 7.5. His-tagged enzyme was eluted using equilibration buffer containing increasing amounts of imidazole $(0-200 \mathrm{mM})$. Purified enzyme was concentrated and exchanged into equilibration buffer using Amicon Ultra- $0.5 \mathrm{~mL}$ centrifugal filters with a $10 \mathrm{kDa}$ molecular weight cut off according to the manufacturer's instructions. MTG yield was quantified using absorbance at $280 \mathrm{~nm}$ (molar extinction coefficient of $55,408 \mathrm{M}^{-1} \mathrm{~cm}^{-1}$ ). The average MTG yield was $10 \mathrm{mg} / \mathrm{L}$ of $E$. coli culture. Purified MTG was snap frozen as single use aliquots containing $15 \%(\mathrm{v} / \mathrm{v})$ glycerol. 


\section{Expression and Purification of Trastuzumab}

HEK293F suspension cells were transfected with the plasmid pVITRO-Trastuzumab-lgG1/k using FreeStyle ${ }^{\mathrm{TM}}$ MAX transfection reagent. Transfected cells were selected with $50 \mu \mathrm{g} / \mathrm{mL}$ hygromycin $B$ for two weeks to establish a stably expressing cell line. Stably expressing HERK293F cells were maintained at density of approximately $1 \times 10^{6}$ cells $/ \mathrm{mL}$ for protein production. Trastuzumab was purified from sterilefiltered, conditioned media using a gravity flow column charged with $1 \mathrm{~mL}$ of protein $A / G$ resin according to the manufacturer's instructions. Purified antibody was concentrated and exchanged into PBS buffer (100 mM phosphate, $150 \mathrm{mM} \mathrm{NaCl}, \mathrm{pH} 7.4$ ) using Amicon Ultra- $0.5 \mathrm{~mL}$ centrifugal filters with a $30 \mathrm{kDa}$ molecular weight cut off according to the manufacturer's instructions. Antibody yield was quantified using absorbance at $280 \mathrm{~nm}$ (molar extinction coefficient of $210,000 \mathrm{M}^{-1} \mathrm{~cm}^{-1}$ ). The average antibody yield was $1-2 \mathrm{mg}$ per/L of conditioned media.

\section{Analysis of Linker Conjugation Efficiency}

\section{Analysis of Linker Purity and Hydrophobicity via HPLC}

Linker purity and relative hydrophobicity were analyzed on an Agilent 1100 Series HPLC system equipped with a UV diode array detector and an 1100 Infinity fraction collector using a reversed-phase C18 column (Agilent Eclipse Plus C18, $4.6 \times 150 \mathrm{~mm}, 5 \mu \mathrm{m}$ ). The mobile phase for HPLC was water with $0.1 \%(\mathrm{v} / \mathrm{v})$ trifluoroacetic acid (solvent $\mathrm{A}$ ) and acetonitrile with $0.1 \%(\mathrm{v} / \mathrm{v})$ trifluoroacetic acid (solvent $\mathrm{B}$ ). Compounds were eluted at a flow rate of $1 \mathrm{~mL} / \mathrm{min}$ with a linear gradient of $5 \%$ to $95 \%$ solvent B over 30 minutes. Linkers were analyzed at a scale of $50 \mu \mathrm{g}$ and monitored based on their methyltetrazine-specific absorption at $360 \mathrm{~nm}$.

\section{HIC Analysis of Linker Conjugation Efficiency}

1 equivalency of trastuzumab ( $250 \mu \mathrm{g}, 1.7 \mathrm{nmol}$ ) at a concentration of $5 \mathrm{mg} / \mathrm{mL}$ in PBS buffer was treated with PNGase F (600 U/mg of antibody), MTG ( 0.75 equivalencies), and amine-bearing substrate (160 equivalencies). Conjugation reactions were carried out at $37^{\circ} \mathrm{C}$ for 24 hours. Excess enzyme and substrate were removed using NAb Protein A/G $0.2 \mathrm{~mL}$ spin columns according to the manufacturer's instructions. Conjugation efficiency was analyzed via analytical HIC using a linear solvent gradient of 0 $-60 \%$ solvent B over 60 minutes.

\section{Gel Electrophoresis Analysis of Linker Conjugation Efficiency}

1 equivalency of trastuzumab $(100 \mu \mathrm{g}, 0.7 \mathrm{nmol})$ at a concentration of $5 \mathrm{mg} / \mathrm{mL}$ in PBS buffer was treated with PNGase F (600 U/mg of antibody), MTG ( 0.75 equivalencies), and amine-bearing substrate (160 equivalencies). Conjugation reactions were carried out at $37^{\circ} \mathrm{C}$ for 24 hours. Excess enzyme and substrate were removed using NAb Protein A/G $0.2 \mathrm{~mL}$ spin columns according to the manufacturer's instructions. Purified conjugates were lyophilized and suspended at a concentration of $5 \mathrm{mg} / \mathrm{mL}$. Conjugates were diluted to a concentration of $1 \mathrm{mg} / \mathrm{mL}$ in PBS buffer, $\mathrm{pH} 7.4$ and reacted with 20 equivalencies of either DBCO-PEG5K (compound 18) or TCO-PEG5K (compound 19). Reactions were carried out at $37^{\circ} \mathrm{C}$ for 20 hours and analyzed by reduced and denatured SDS-PAGE. Conjugation efficiency was quantified by analyzing the relative band intensities for the IgG heavy chain and the PEG5K-modified heavy chain. Each band was quantified relative to the IgG light chain band as an internal control. Band intensities were quantified using the gel analysis tool of $\mathrm{FIJI}^{2}$ Raw images are provided and quantified (Figure S29 and S30). 


\section{Characterization of Conjugate T5 and Antibody-drug Conjugates}

\section{Large Scale Purification of Conjugate T5}

1 equivalency of trastuzumab $(2.3 \mathrm{mg}, 15.3 \mathrm{nmol})$ at a concentration of $5 \mathrm{mg} / \mathrm{mL}$ in PBS buffer was treated with PNGase F (600 U/mg of antibody), MTG (0.75 equivalencies), and Linker 5 (160 equivalencies). The reaction was carried out at $37^{\circ} \mathrm{C}$ for 24 hours and then purified via analytical HIC using a linear solvent gradient of $0-60 \%$ solvent B over 60 minutes. The product (conjugate T5) eluted at 47 minutes. The product was concentrated and exchanged into PBS buffer, $\mathrm{pH} 7.4$ using Amicon Ultra- $0.5 \mathrm{~mL}$ centrifugal filters with a $30 \mathrm{kDa}$ molecular weight cut off according to the manufacturer's instructions. Conjugate was recovered in $48 \%$ yield $(1.1 \mathrm{mg}, 7.3 \mathrm{nmol})$. Conjugate purity was assessed via analytical HIC using a linear solvent gradient from $0-100 \%$ solvent B over 60 minutes (Figure S31). Conjugate molecular weight was characterized via MALDI-MS (Figure S32).

\section{Gel Electrophoresis Analysis of Dual "Click" Modification}

1 equivalency of conjugate T5 (50 ug, $0.33 \mathrm{nmol}$ ) at a concentration of $6 \mathrm{mg} / \mathrm{mL}$ in PBS buffer was reacted with 2 equivalencies of DBCO-PEG4-Carboxyrhodamine101, sulfo-Cy5-TCO, or both. Reactions were carried out protected from light at room temperature for 20 hours and analyzed by reduced and denatured SDS-PAGE. Fluorescence imaging was performed using a GE Healthcare Typhoon 9400 image system set to a photomultiplier tube voltage of 400 with the following fluorescence settings: Carboxyrhodamine101 excitation $488 \mathrm{~nm}$, emission $500-540 \mathrm{~nm}$; sulfo-Cy5 excitation $633 \mathrm{~nm}$, emission $655-685 \mathrm{~nm}$; FRET excitation $488 \mathrm{~nm}$, emission $655-685 \mathrm{~nm}$. A reaction scheme is provided (Figure S33).

\section{One-pot Synthesis of Antibody-drug Conjugates}

1 equivalency of conjugate T5 (80 ug, $0.53 \mathrm{nmol}$ ) at a concentration of $6 \mathrm{mg} / \mathrm{mL}$ in PBS buffer was reacted with 2 equivalencies of DBCO-PEG28 (compound 20), TCO-PEG24-DM1 (compound 21), or both. Reactions were carried out at room temperature for 20 hours. Excess reagents were removed using Amicon Ultra- $0.5 \mathrm{~mL}$ centrifugal filters with a $30 \mathrm{kDa}$ molecular weight cut off according to the manufacturer's instructions. Conjugation efficiency was assessed via analytical HIC using a linear solvent gradient from $0-100 \%$ solvent B over 60 minutes. A reaction scheme is provided (Figure S34). Conjugate molecular weight was characterized via MALDI-MS (Figure S35).

\section{In Vitro Potency of Antibody-drug Conjugates}

SKOV3 and MCF7 cells were plated at 6,000 and 1,500 cells/well, respectively, and allowed to adhere overnight. After overnight incubation, three-fold serial dilutions of the conjugates or DM1-S-Me control starting at $33 \mathrm{nM}$ were added. Treated cells were then incubated for 4 days. Cell viability was measured using MTS according to the manufacturer's instructions using a Tecan Infinite M1000 Pro microplate reader. Percent viability was calculated by comparison to untreated cells and media alone. Potency data for MCF7, a Her2 negative cell line, is provided (Figure S36). 


\section{Results and Discussion}

Synthesis of Antibody Modification Reagents

Synthesis of Linker 1 (compound 3)

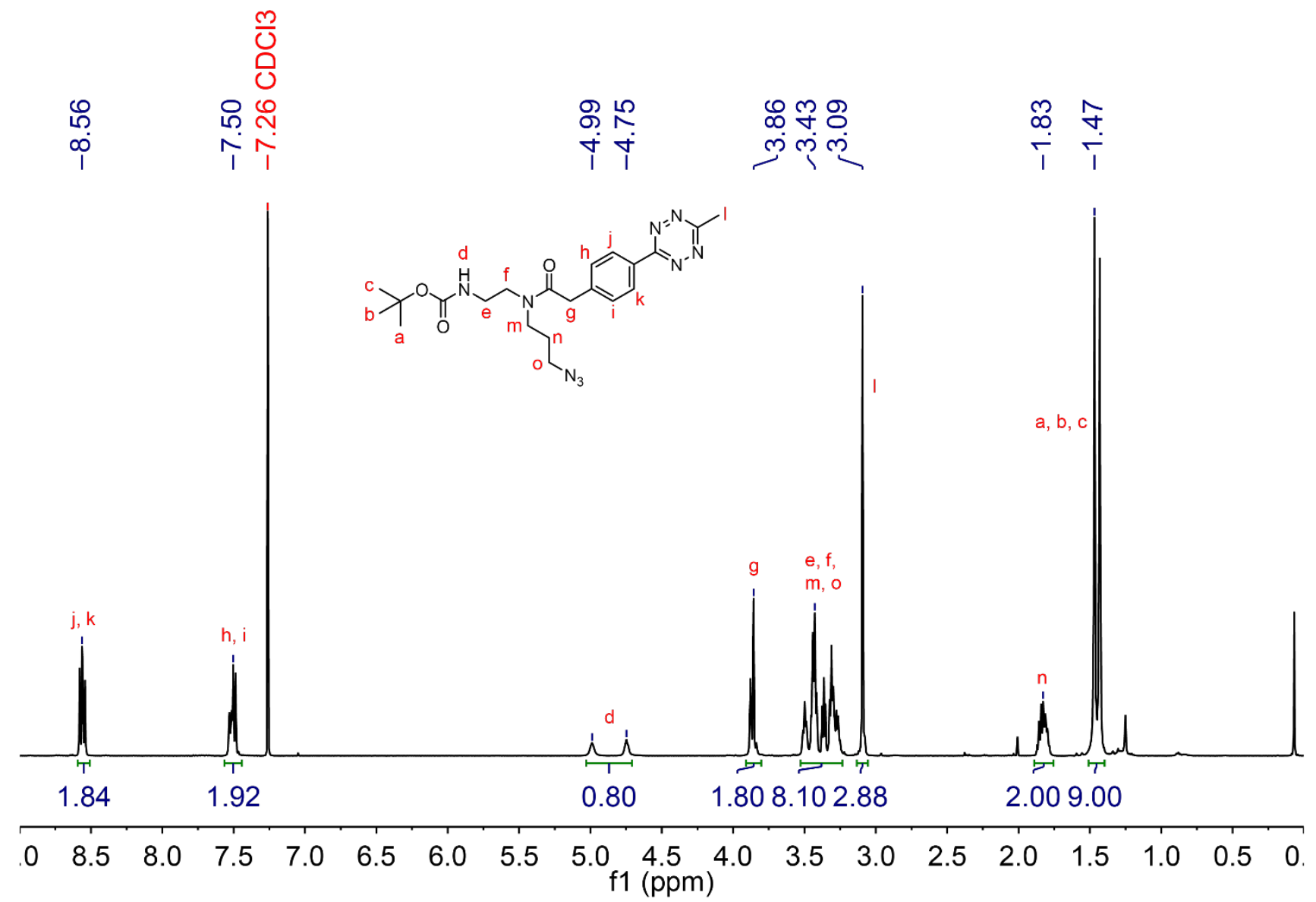

Supplementary Figure S11. ${ }^{1} \mathrm{H}$ NMR $\left(500 \mathrm{MHz}, \mathrm{CDCl}_{3}\right)$ of compound (2). 


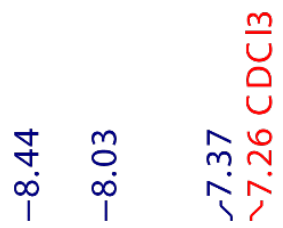

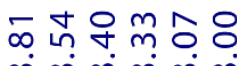

rim $\dot{m} \dot{m} \dot{m}$

$\stackrel{1}{\stackrel{1}{2}}$
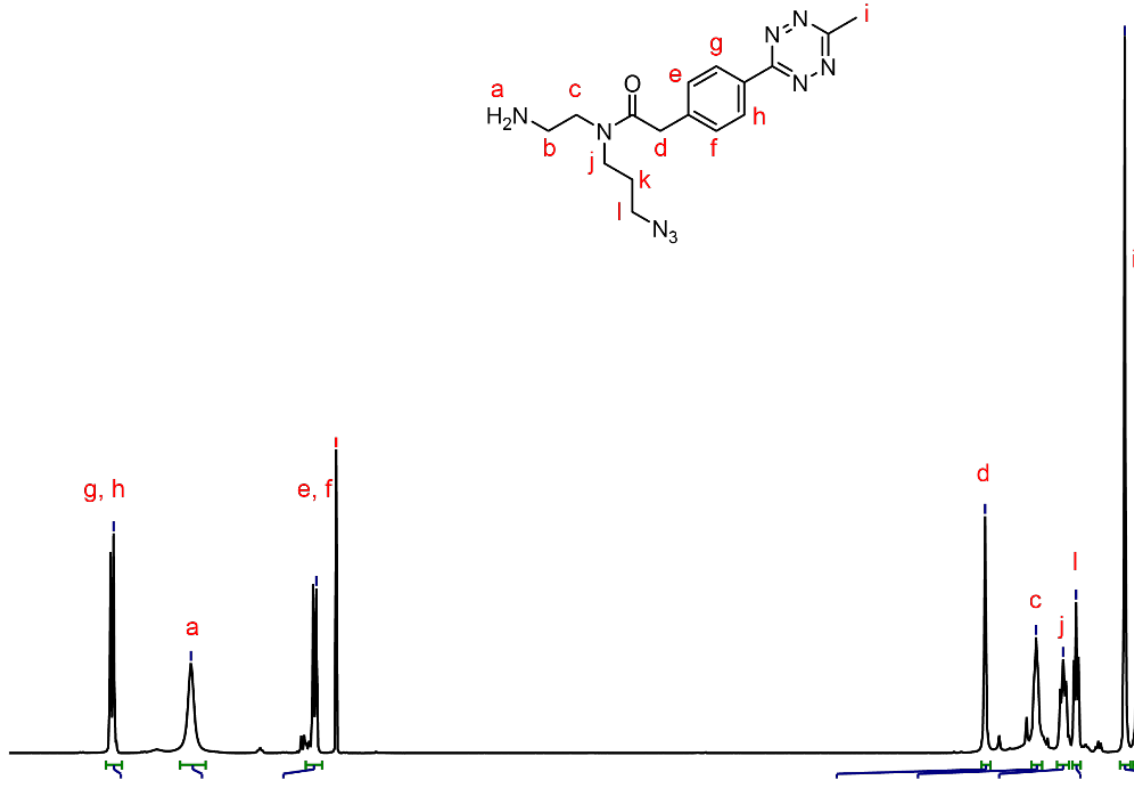

2.382 .892 .22

$$
2.002 .472 .312 .123 .752 .11 \quad 2.25
$$

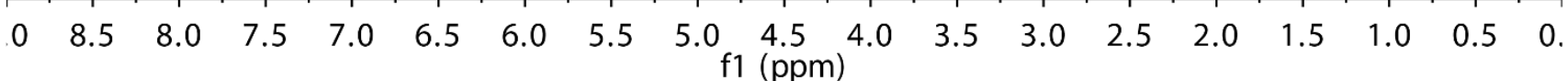

Supplementary Figure S12. ${ }^{1} \mathrm{H}$ NMR (500 MHz, $\left.\mathrm{CDCl}_{3}\right)$ of compound (3). 
Synthesis of 1-azido-2-(2-(2-bromoethoxy)ethoxy)ethane (Compound 6)

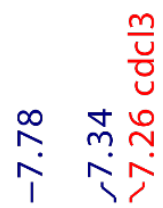

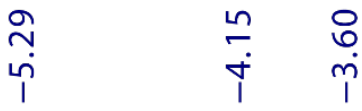

$\stackrel{m}{\mathfrak{r}}$

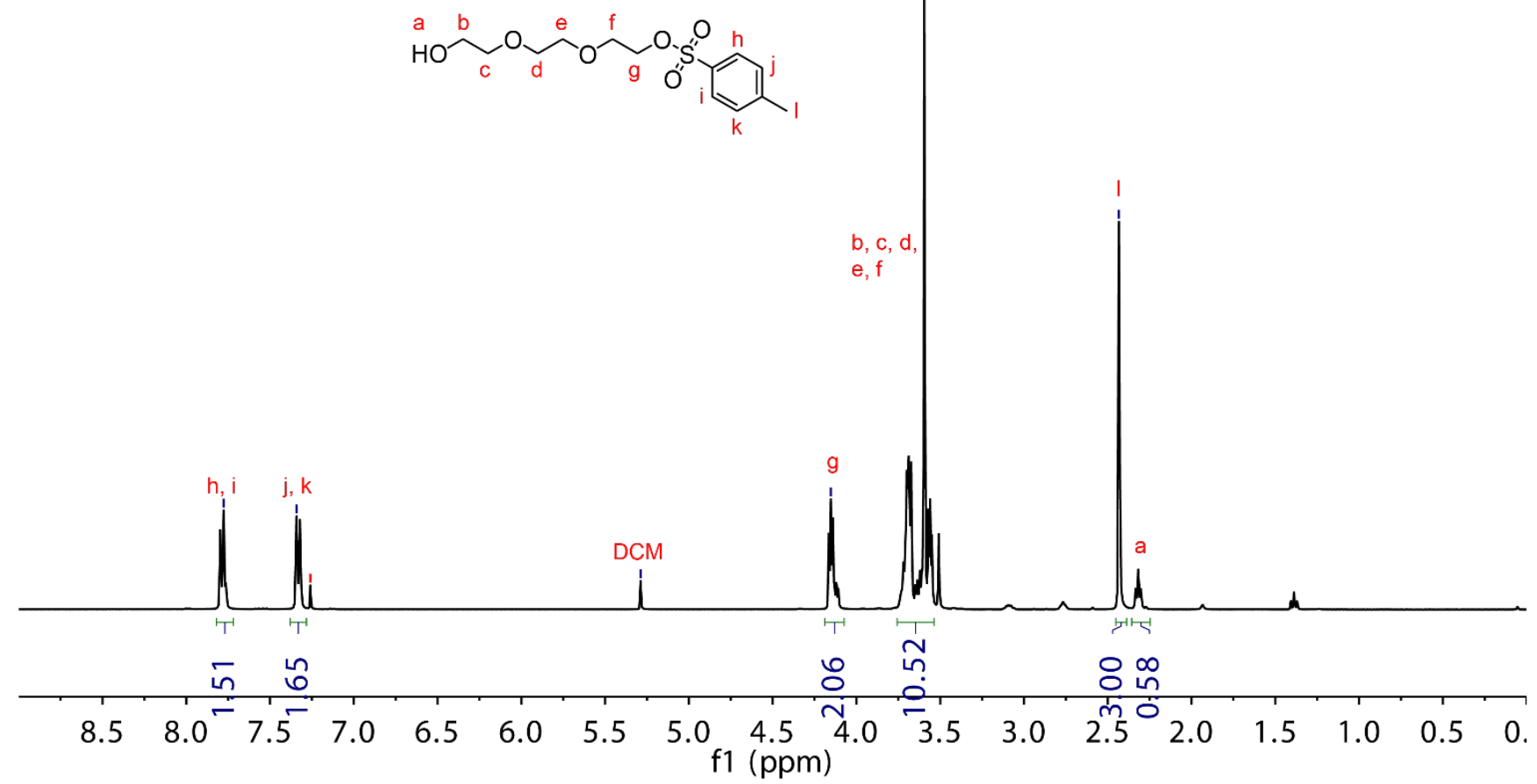

Supplementary Figure S13. ${ }^{1} \mathrm{H}$ NMR (400 MHz, $\left.\mathrm{CDCl}_{3}\right)$ of compound (4). 


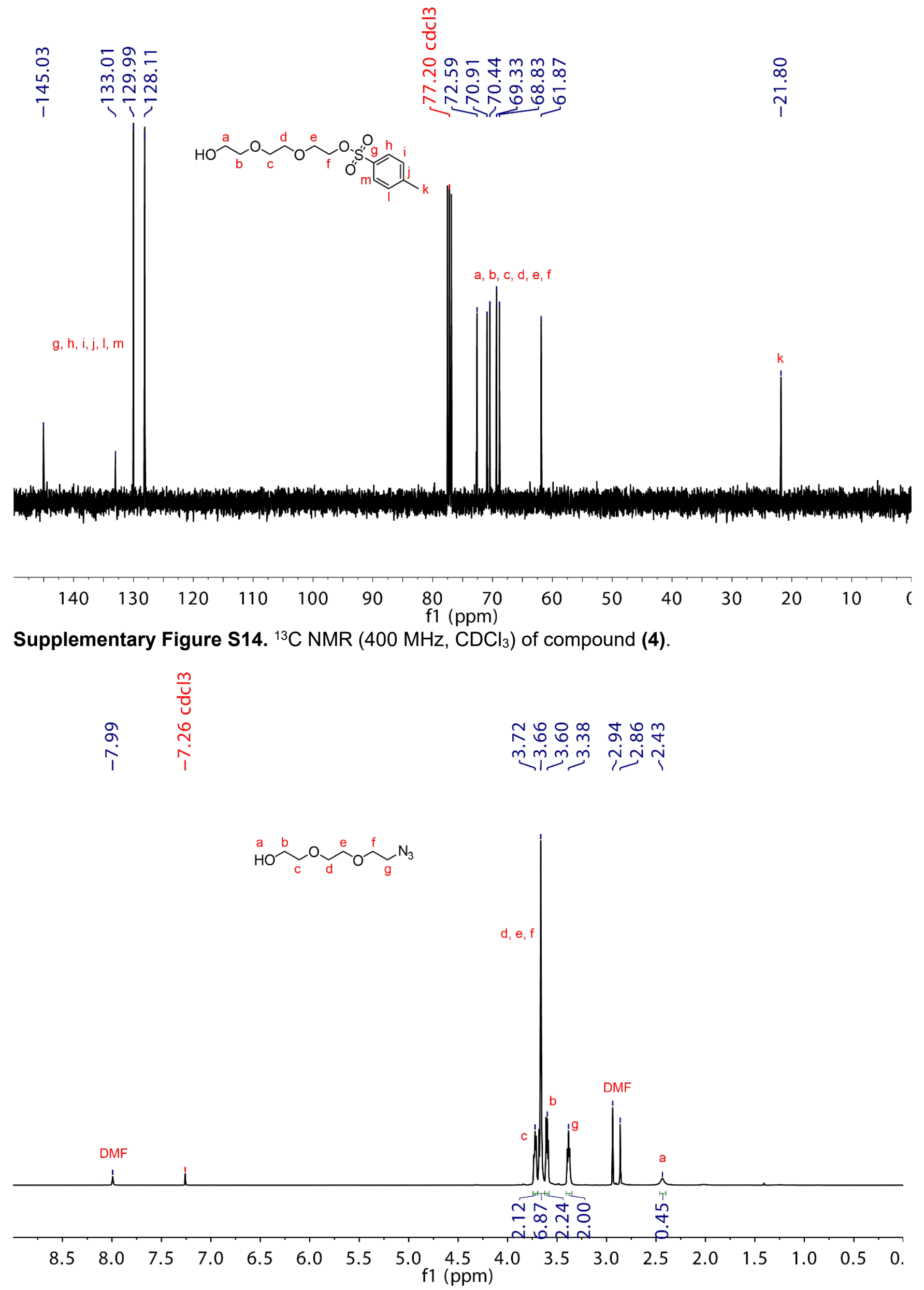

Supplementary Figure S15. ${ }^{1} \mathrm{H}$ NMR $\left(400 \mathrm{MHz}, \mathrm{CDCl}_{3}\right)$ of compound (5). 


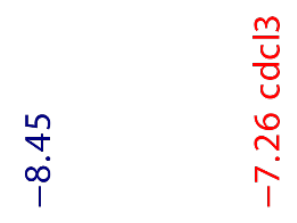

용 f

miñminj

$\overbrace{\mathrm{b}}^{\mathrm{a}} \mathrm{O} \overbrace{\mathrm{c}}^{\mathrm{d}} \overbrace{\mathrm{O}}^{\mathrm{e}} \overbrace{3}$

, c, d

b

DMF

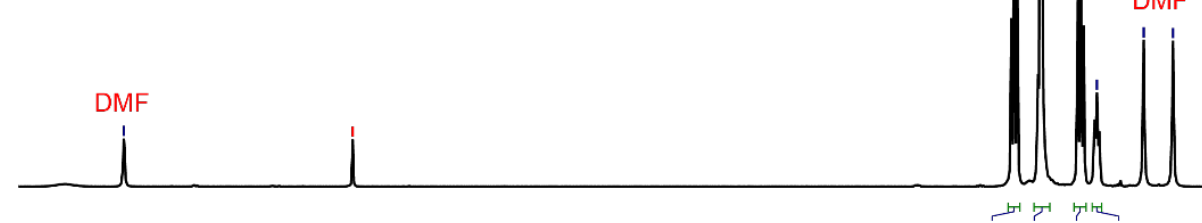

ํํㅇㅇㅛ

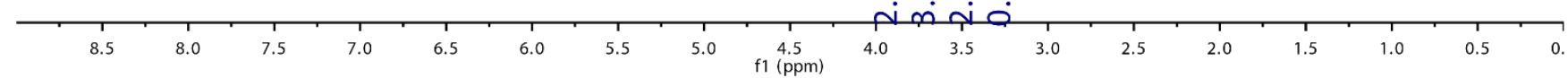

Supplementary Figure S16. ${ }^{1} \mathrm{H}$ NMR $\left(400 \mathrm{MHz}, \mathrm{CDCl}_{3}\right)$ of compound (6).

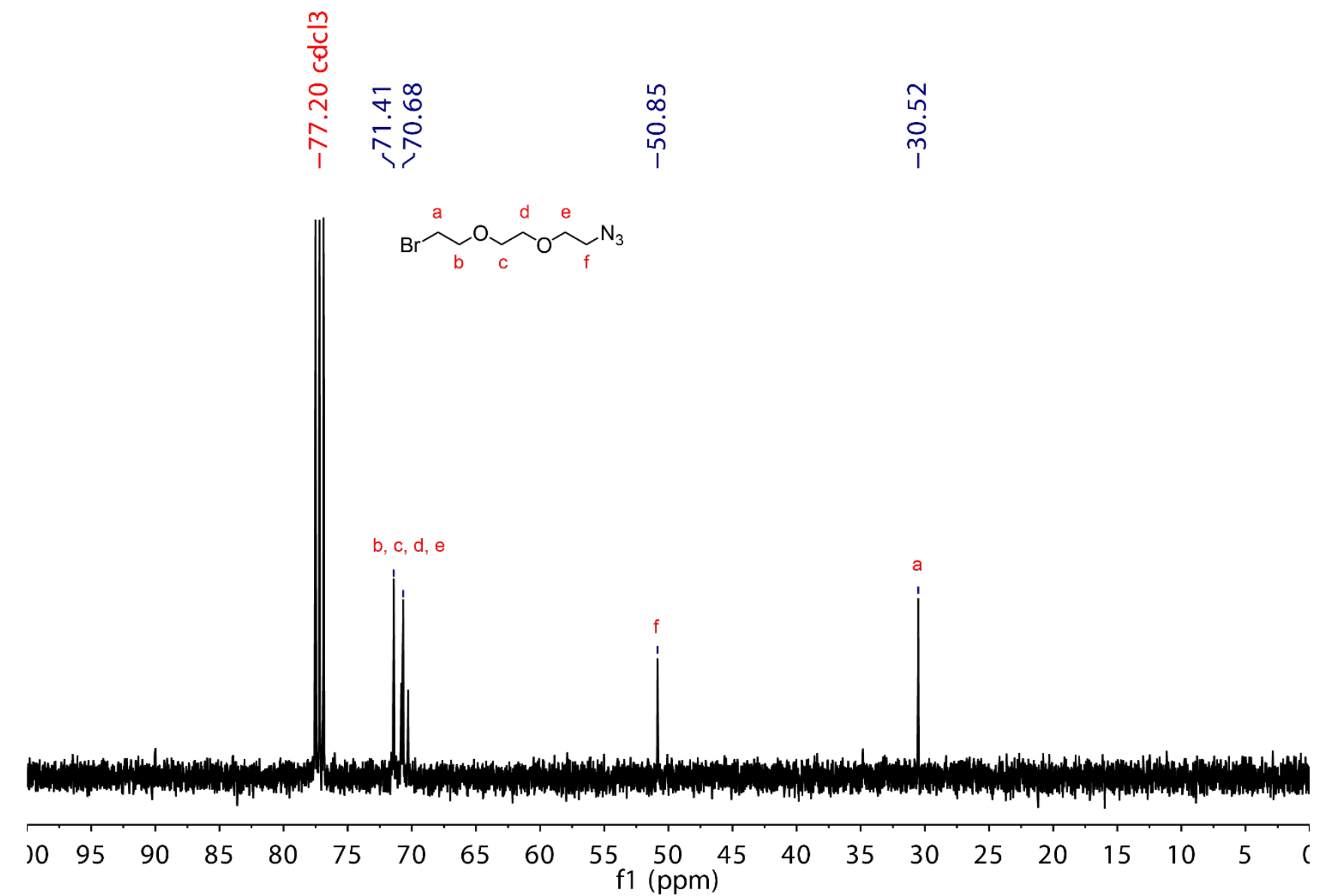

Supplementary Figure S17. ${ }^{13} \mathrm{C}$ NMR $\left(400 \mathrm{MHz}, \mathrm{CDCl}_{3}\right)$ of compound (6). 


\section{Synthesis of Linker 2 (Compound 9)}

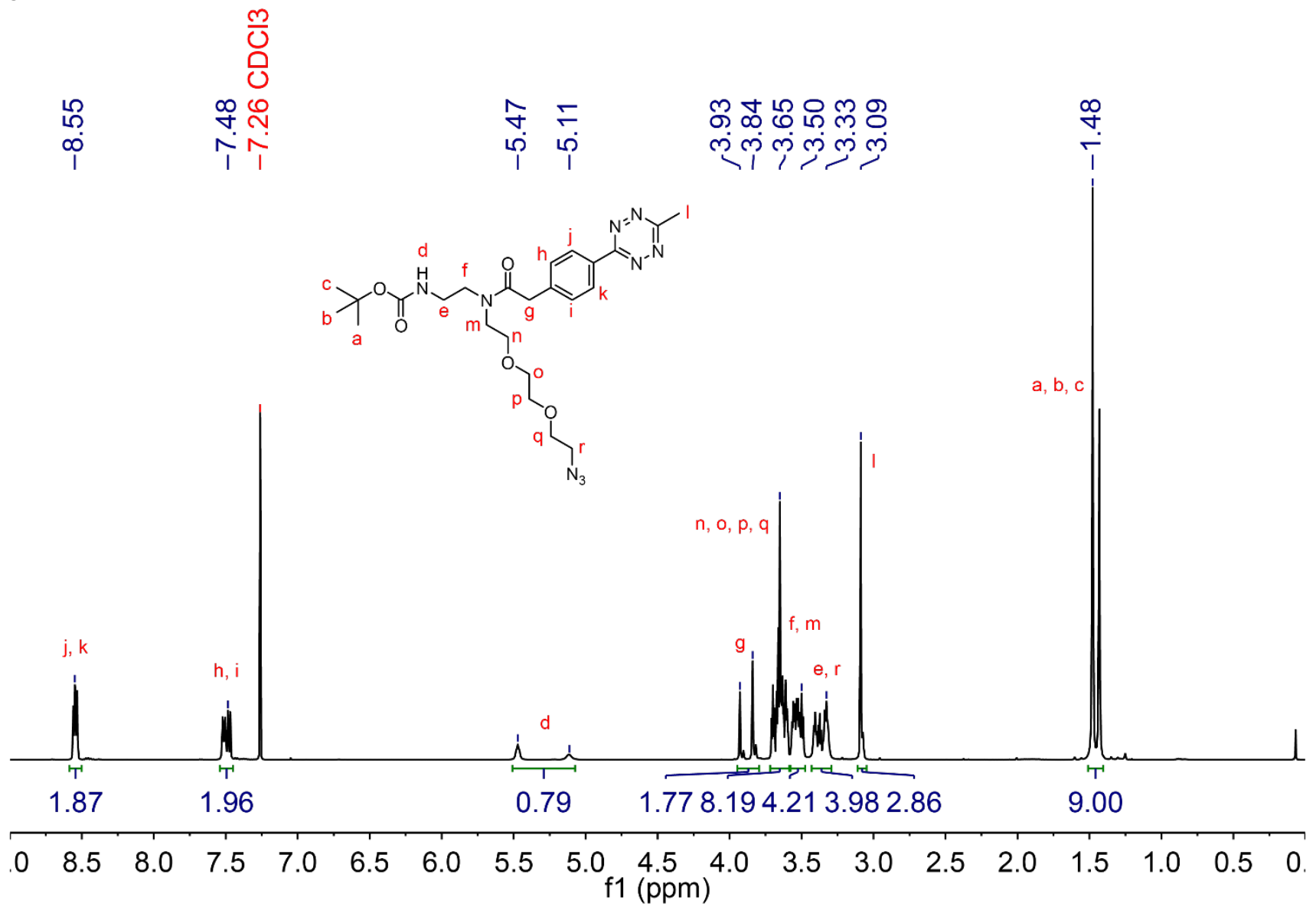

Supplementary Figure S18. ${ }^{1} \mathrm{H}$ NMR $\left(500 \mathrm{MHz}, \mathrm{CDCl}_{3}\right)$ of compound (8).

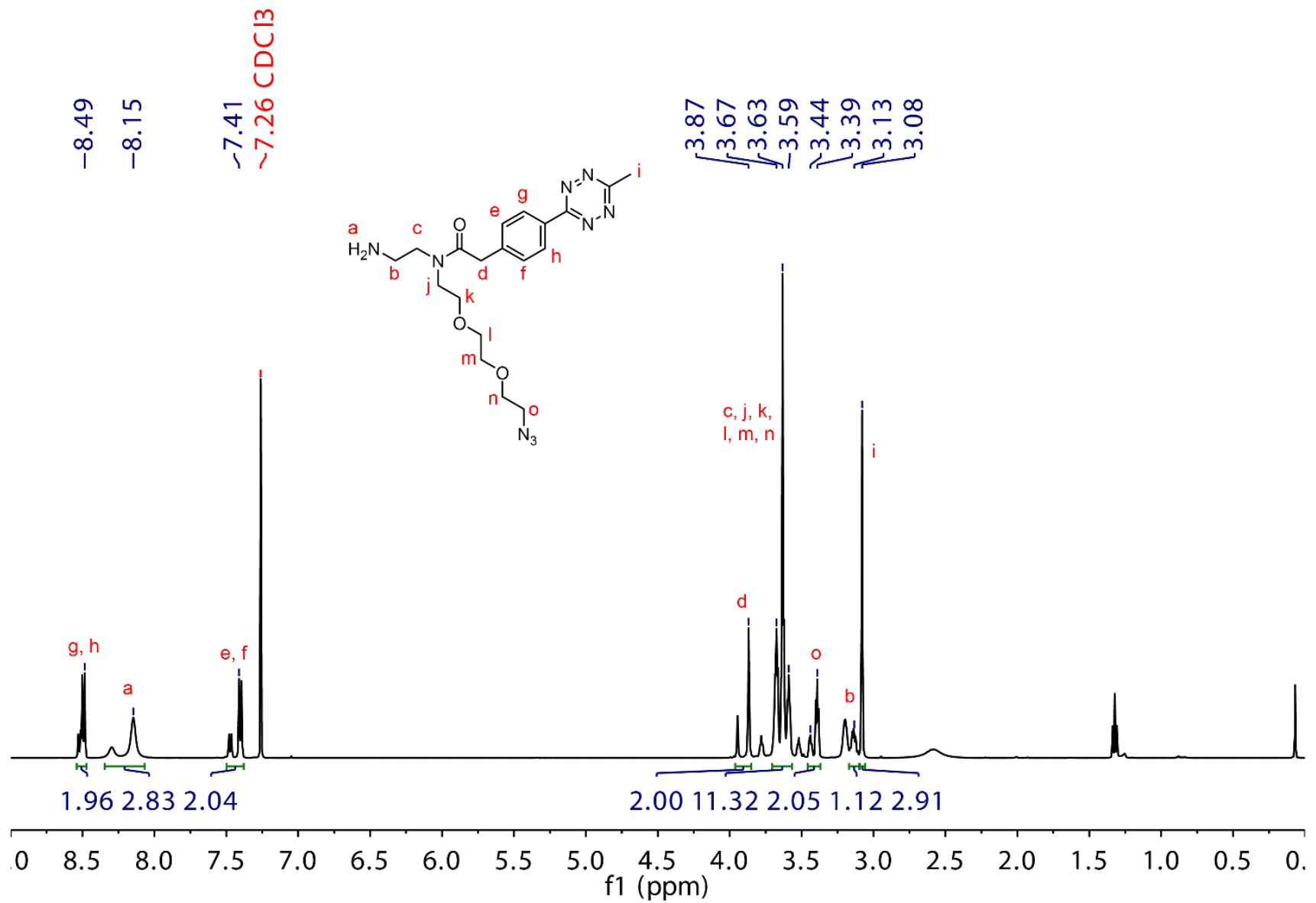

Supplementary Figure S19. ${ }^{1} \mathrm{H}$ NMR $\left(500 \mathrm{MHz}, \mathrm{CDCl}_{3}\right)$ of compound (9). 
Synthesis of Linker 3 (Compound 11)

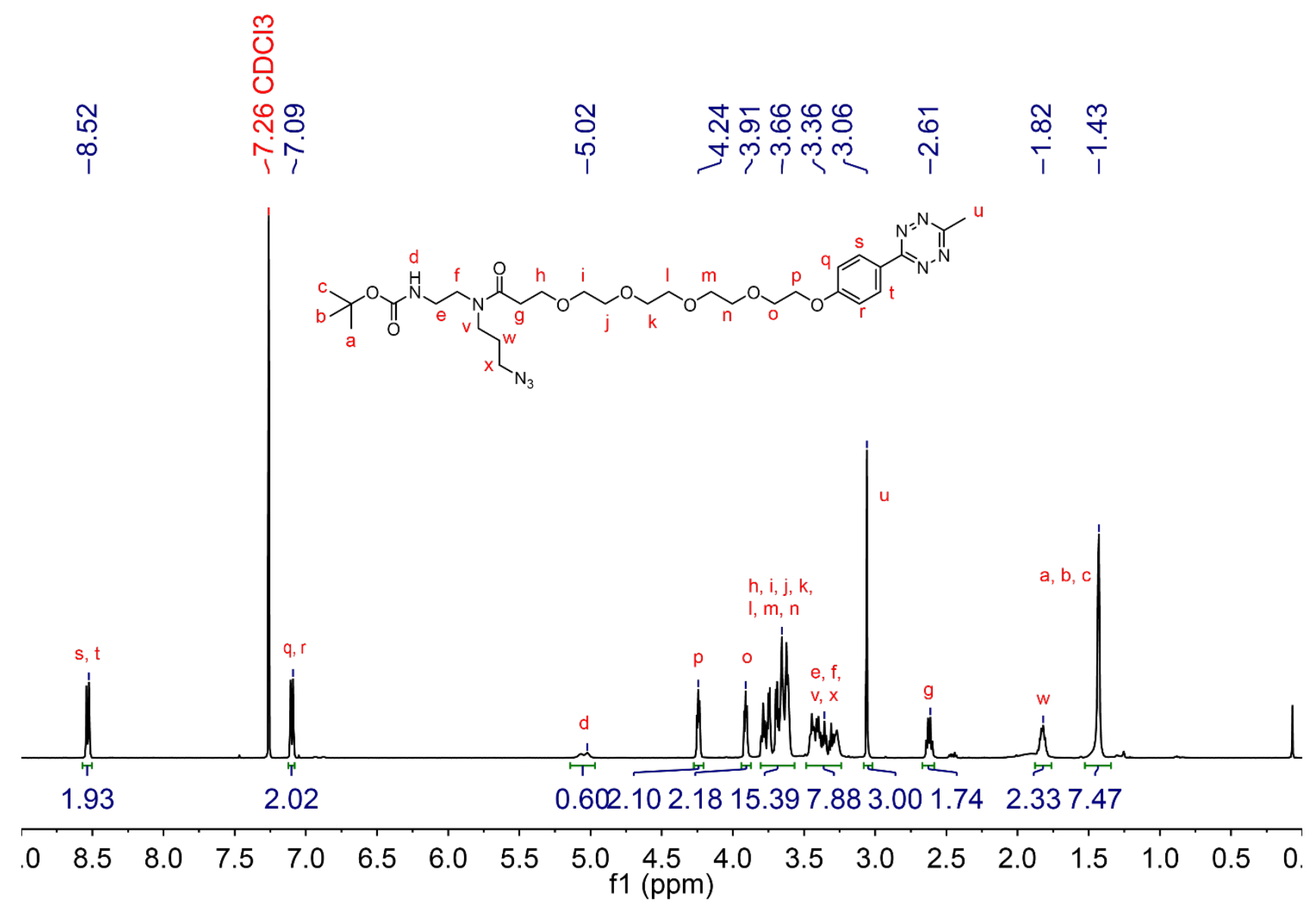

Supplementary Figure S20. ${ }^{1} \mathrm{H}$ NMR $\left(500 \mathrm{MHz}, \mathrm{CDCl}_{3}\right)$ of compound (10). 


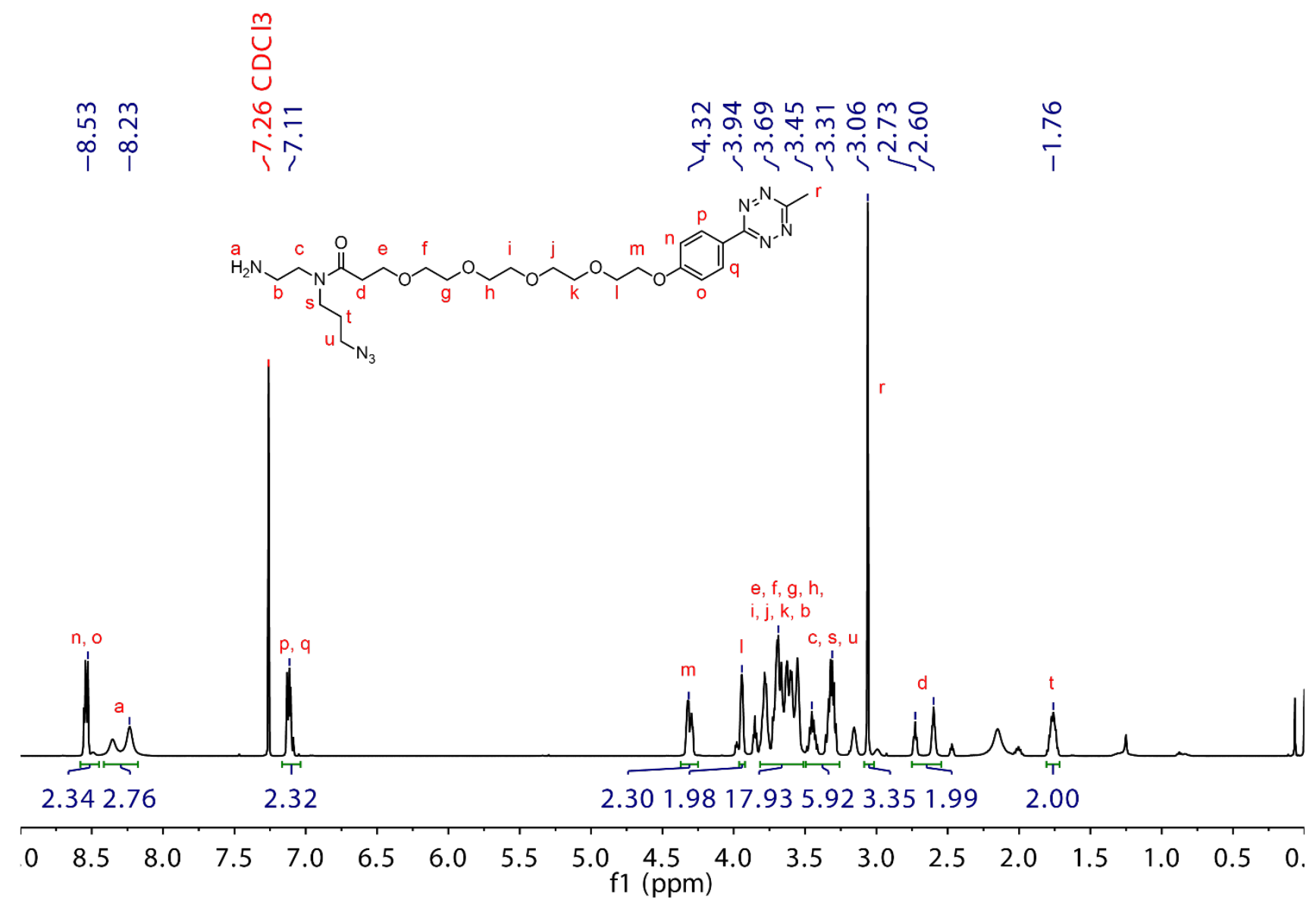

Supplementary Figure S21. ${ }^{1} \mathrm{H}$ NMR $\left(500 \mathrm{MHz}, \mathrm{CDCl}_{3}\right)$ of compound (11). 
Synthesis of Linker 4 (Compound 14)

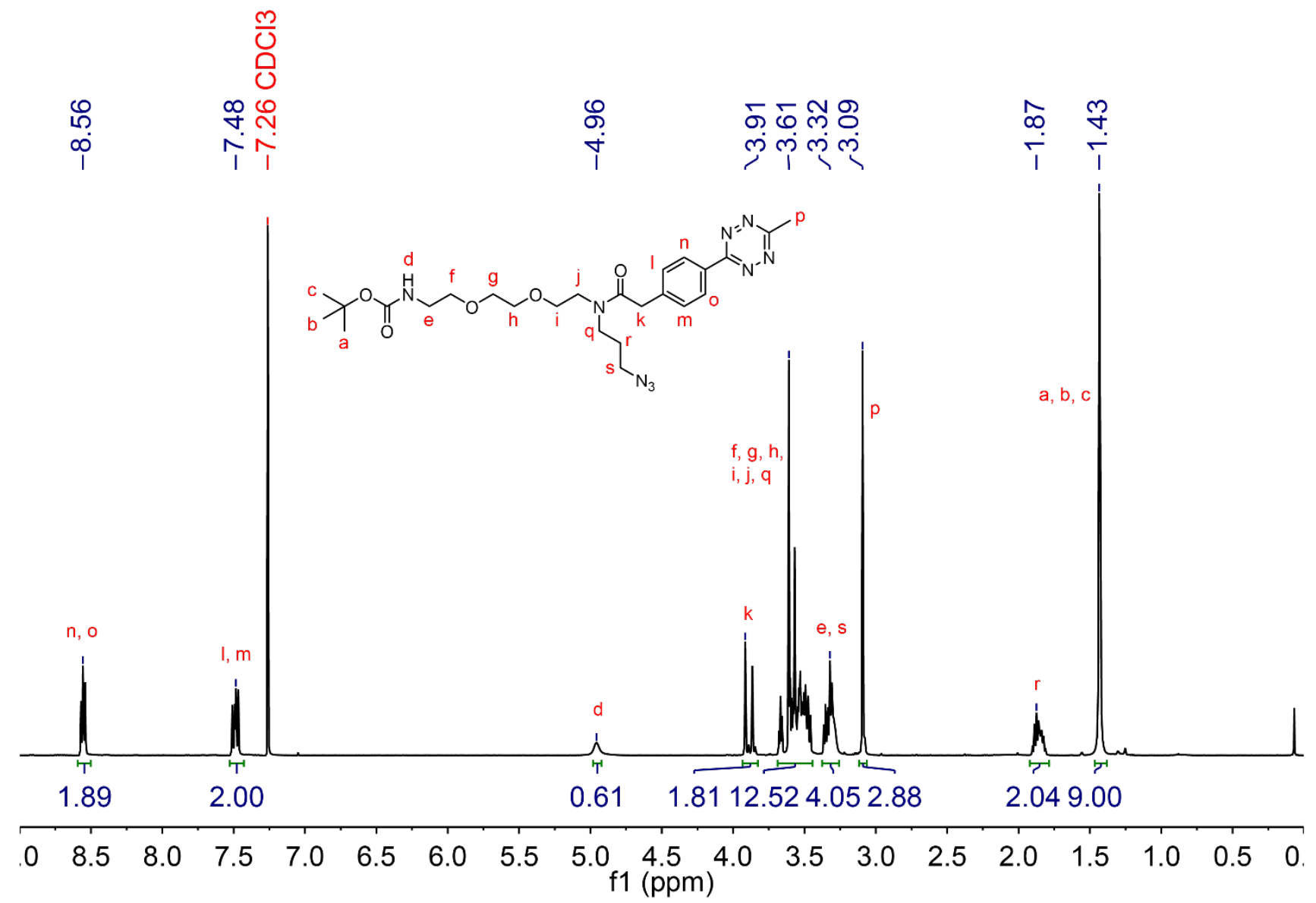

Supplementary Figure S22. ${ }^{1} \mathrm{H}$ NMR $\left(500 \mathrm{MHz}, \mathrm{CDCl}_{3}\right)$ of compound (13). 


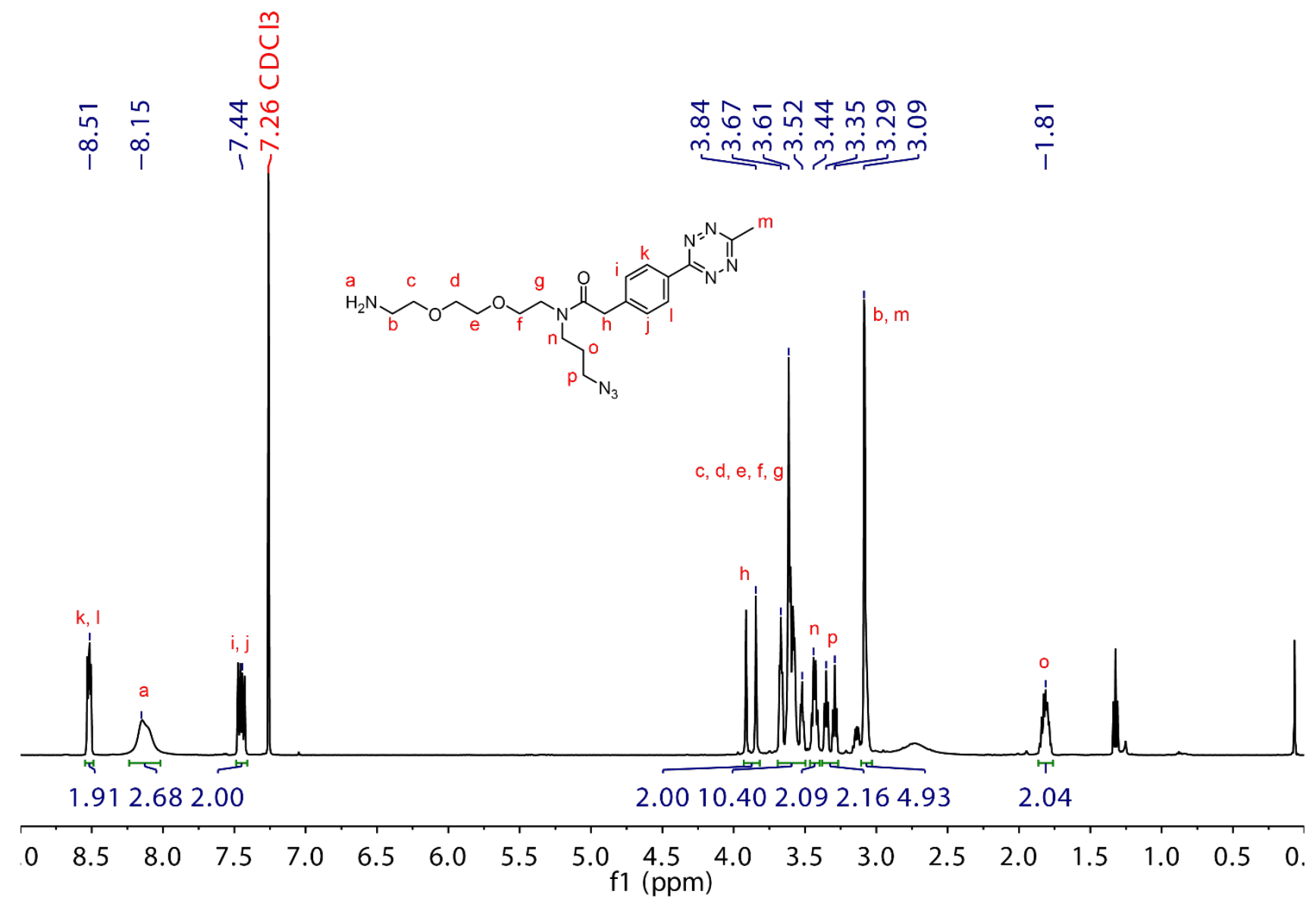

Supplementary Figure S23. ${ }^{1} \mathrm{H}$ NMR $\left(500 \mathrm{MHz}, \mathrm{CDCl}_{3}\right)$ of compound (14). 
Synthesis of Linker 5 (Compound 17)

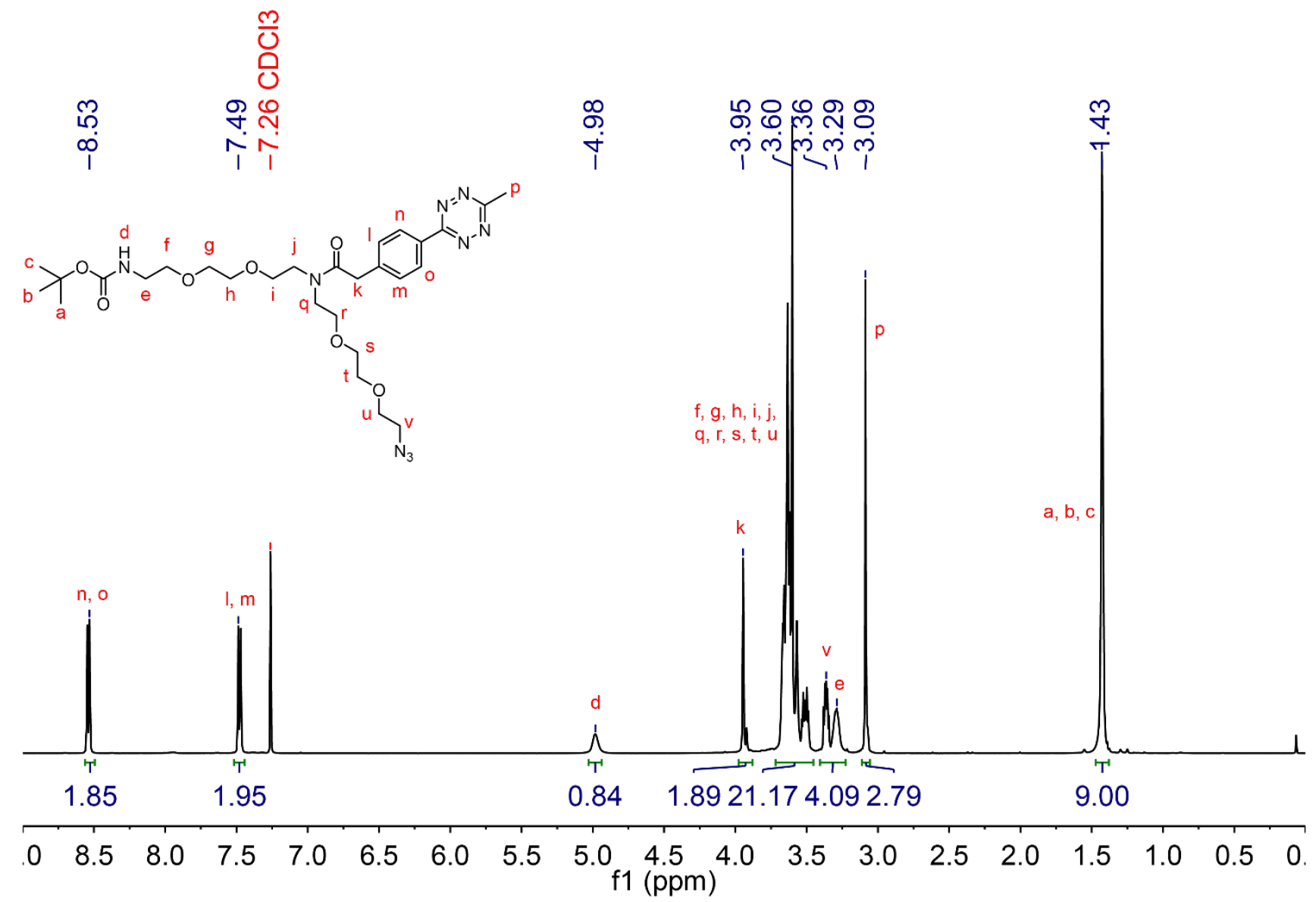

Supplementary Figure S24. ${ }^{1} \mathrm{H}$ NMR $\left(500 \mathrm{MHz}, \mathrm{CDCl}_{3}\right)$ of compound (16). 


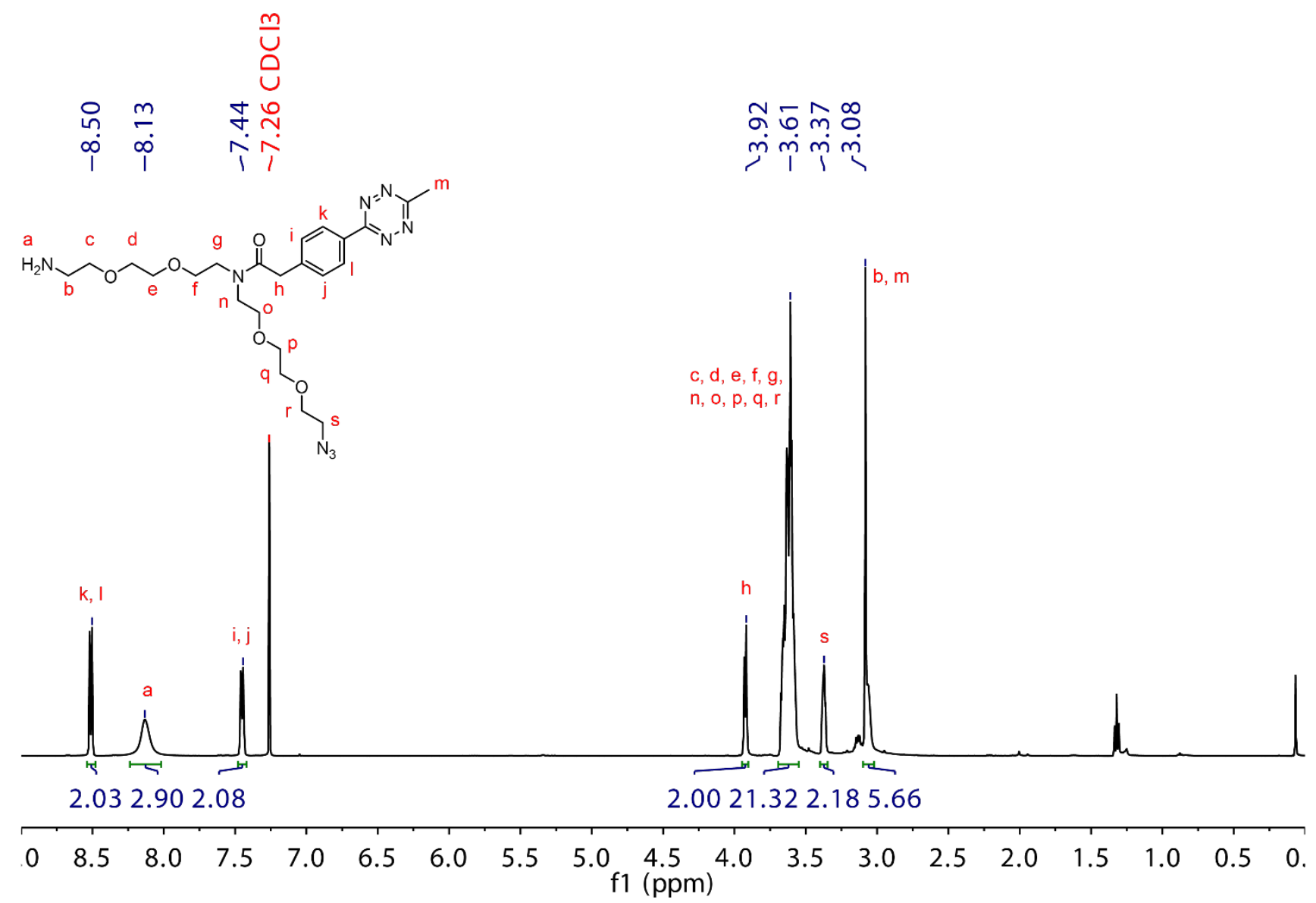

Supplementary Figure S25. ${ }^{1} \mathrm{H}$ NMR $\left(500 \mathrm{MHz}, \mathrm{CDCl}_{3}\right)$ of compound (17). 


\section{Synthesis of DBCO-PEG5K (Compound 18)}

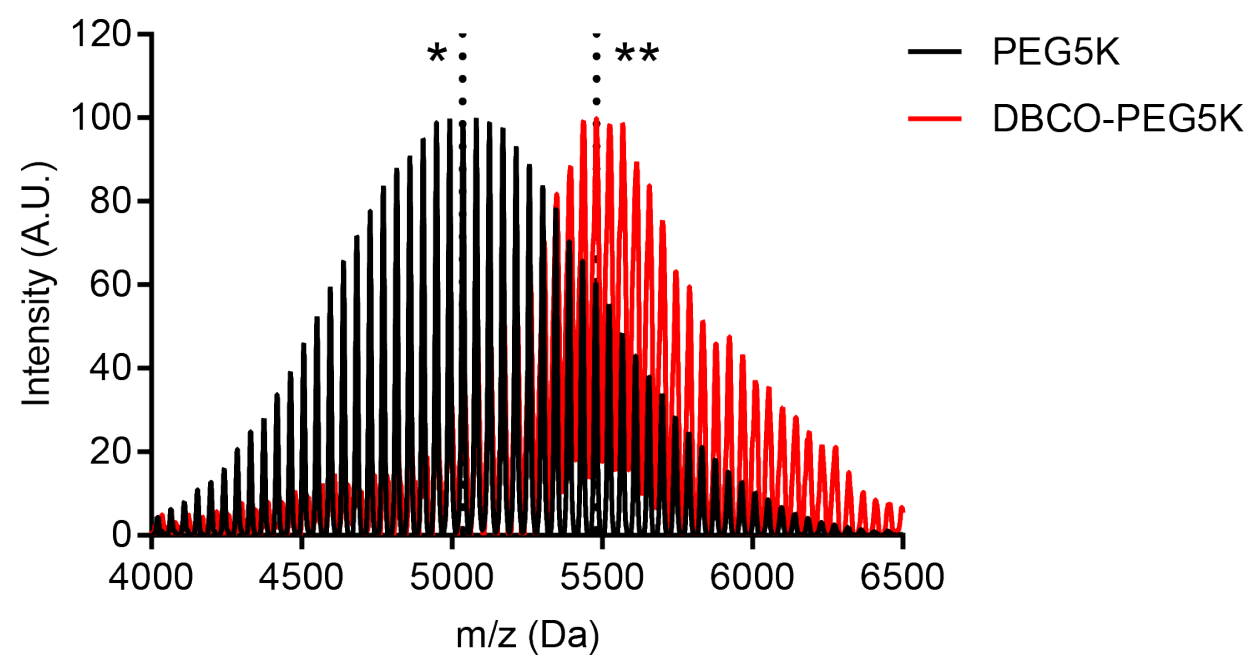

Supplementary Figure S26. MALDI-MS of compound (18). Center of the distribution for the unmodified PEG5K $\left({ }^{*}\right)$ was at 5,036 Da. Center of the distribution for the DBCO-modified PEG5K $\left(^{* *}\right)$ was at 5,481 Da. Observed difference: $445 \mathrm{Da}$, Expected Difference: $408 \mathrm{Da}$.

\section{Synthesis of TCO-PEG5K (Compound 19)}

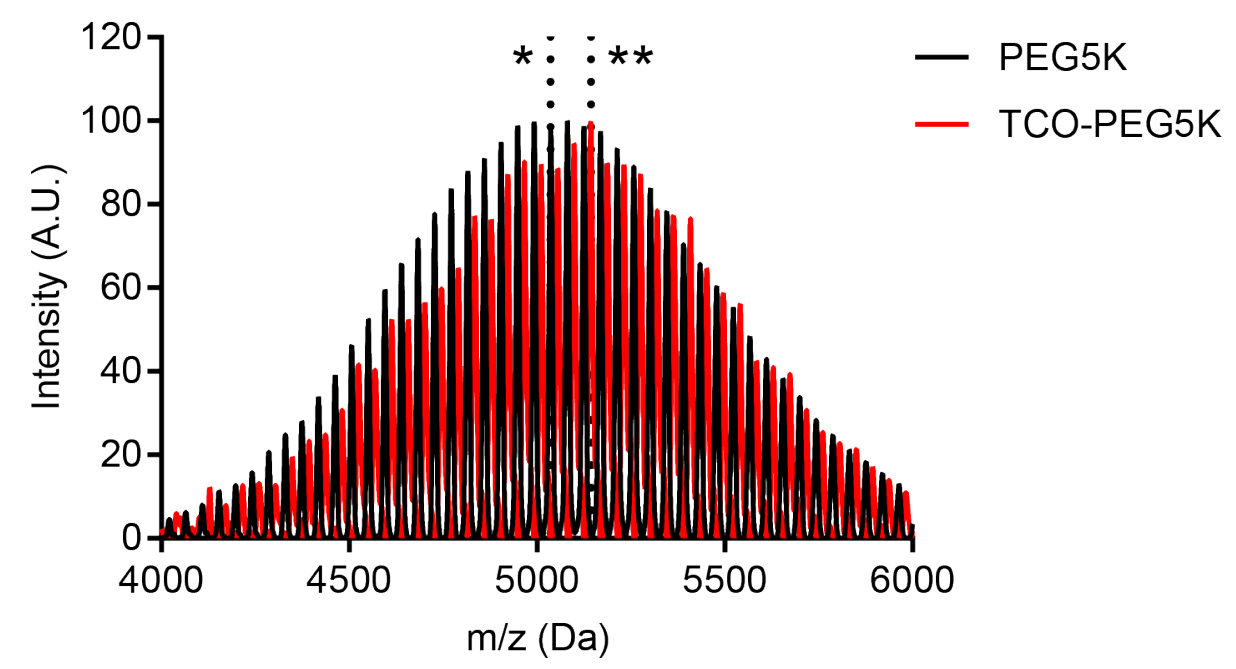

Supplementary Figure S27. MALDI-MS of compound (19). Center of the distribution for the unmodified PEG5K $\left({ }^{*}\right)$ was at 5,036 Da. Center of the distribution for the TCO-modified PEG5K $\left({ }^{* *}\right)$ was at 5,143 Da. Observed difference: $107 \mathrm{Da}$, Expected Difference: $111 \mathrm{Da}$. 


\title{
Synthesis of TCO-PEG24-DM1 (Compound 21)
}
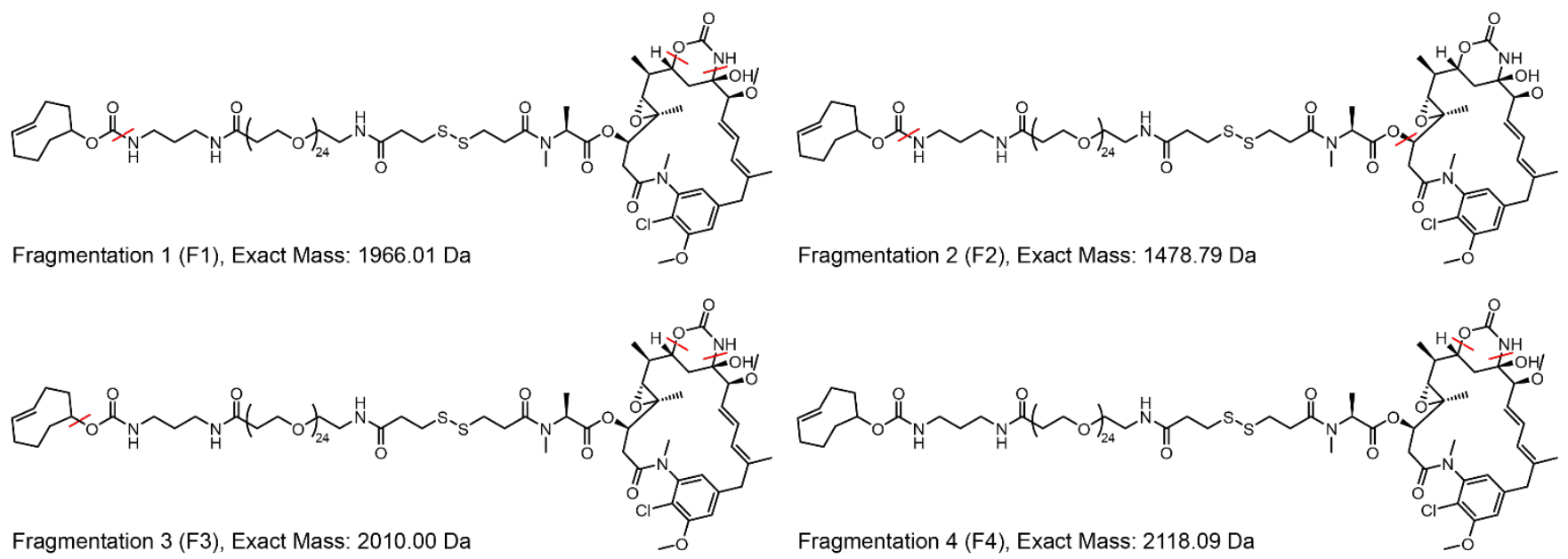

$$
\begin{array}{r}
982.90 \\
100.0 \%
\end{array} \mathrm{~m} / \mathrm{z}=[\mathrm{F} 1] / 2
$$

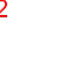




\section{Protein Expression and Purification}

\section{Expression and Purification of Microbial Transglutaminase}

Supplementary Table 1. Sequencing information for microbial transglutaminase. Underlined text indicates the $\mathrm{N}$-terminal pro-sequence.

\begin{tabular}{|c|c|}
\hline & Sequence \\
\hline $\begin{array}{c}\text { Forward } \\
\text { Primer (T7) }\end{array}$ & TAATACGACTCACTATAGGG \\
\hline $\begin{array}{c}\text { Reverse } \\
\text { Primer (T7) }\end{array}$ & GCTAGTTATTGCTCAGCGG \\
\hline $\begin{array}{c}\text { DNA } \\
\text { Sequence }\end{array}$ & $\begin{array}{l}\text { ATGGACAATGGCGCGGGGGAAGAGACGAAGTCCTACGCCGAAACCTACCGCCTC } \\
\text { ACGGCGGATGACGTCGCGAACATCAACGCGCTCAACGAAAGCGCTCCGGCCGC } \\
\text { TTCGAGCGCCGGCCCGTCGTTCCGGGCCCCCGACTCCGACGACAGGGTCACCC } \\
\text { CTCCCGCCGAGCCGCTCGACAGGATGCCCGACCCGTACCGTCCCTCGTACGGC } \\
\text { AGGGCCGAGACGGTCGTCAACAACTACATACGCAAGTGGCAGCAGGTCTACAGC } \\
\text { CACCGCGACGGCAGGAAGCAGCAGATGACCGAGGAGCAGCGGGAGTGGCTGTC } \\
\text { CTACGGCTGCGTCGGTGTCACCTGGGTCAATTCGGGTCAGTACCCGACGAACAG } \\
\text { ACTGGCCTTCGCGTCCTTCGACGAGGACAGGTTCAAGAACGAGCTGAAGAACGG } \\
\text { CAGGCCCCGGTCCGGCGAGACGCGGGCGGAGTTCGAGGGCCGCGTCGCGAAG } \\
\text { GAGAGCTTCGACGAGGAGAAGGGCTTCCAGCGGGCGCGTGAGGTGGCGTCCGT } \\
\text { CATGAACAGGGCCCTGGAGAACGCCCACGACGAGAGCGCTTACCTCGACAACCT } \\
\text { CAAGAAGGAACTGGCGAACGGCAACGACGCCCTGCGCAACGAGGACGCCCGTT } \\
\text { CCCCGTTCTACTCGGCGCTGCGGAACACGCCGTCCTTCAAGGAGCGGAACGGA } \\
\text { GGCAATCACGACCCGTCCAGGATGAAGGCCGTCATCTACTCGAAGCACTTCTGG } \\
\text { AGCGGCCAGGACCGGTCGAGTTCGGCCGACAAGAGGAAGTACGGCGACCCGGA } \\
\text { CGCCTTCCGCCCCGCCCCGGGCACCGGCCTGGTCGACATGTCGAGGGACAGGA } \\
\text { ACATTCCGCGCAGCCCCACCAGTCCCGGTGAGGGATTCGTCAATTCGACTACG } \\
\text { GCTGGTTCGGCGCCCAGACGGAAGCGGACGCCGACAAGACCGTCTGGACCCAC } \\
\text { GGAAATCACTATCACGCGCCCAATGGCAGCCTGGGTGCCATGCATGTCTACGAG } \\
\text { AGCAAGTTCCGCAACTGGTCCGAGGGTTACTCGGACTTCGACCGCGGAGCCTAT } \\
\text { GTGATCACCTTCATCCCCAAGAGCTGGAACACCGCCCCCGACAAGGTAAAGCAG } \\
\text { GGCTGGCCGCTCGAGCACCACCACCACCACCACTGA }\end{array}$ \\
\hline $\begin{array}{c}\text { Amino Acid } \\
\text { Sequence }\end{array}$ & $\begin{array}{l}\text { MDNGAGEETKSYAETYRLTADDVANINALNESAPAASSAGPSFRAPDSDDRVTPPAE } \\
\text { PLDRMPDPYRPSYGRAETVVNNYIRKWQQVYSHRDGRKQQMTEEQREWLSYGCV } \\
\text { GVTWVNSGQYPTNRLAFASFDEDRFKNELKNGRPRSGETRAEFEGRVAKESFDEEK } \\
\text { GFQRAREVASVMNRALENAHDESAYLDNLKKELANGNDALRNEDARSPFYSALRNT } \\
\text { PSFKERNGGNHDPSRMKAVIYSKHFWSGQDRSSSADKRKYGDPDAFRPAPGTGLV } \\
\text { DMSRDRNIPRSPTSPGEGFVNFDYGWFGAQTEADADKTVWTHGNHYHAPNGSLGA } \\
\text { MHVYESKFRNWSEGYSDFDRGAYVITFIPKSWNTAPDKVKQGWPLEHHHHHH }\end{array}$ \\
\hline
\end{tabular}


Analysis of Linker Conjugation Efficiency

Gel Electrophoresis Analysis of Linker Conjugation Efficiency

A

B

(+) DBCO-PEG5K

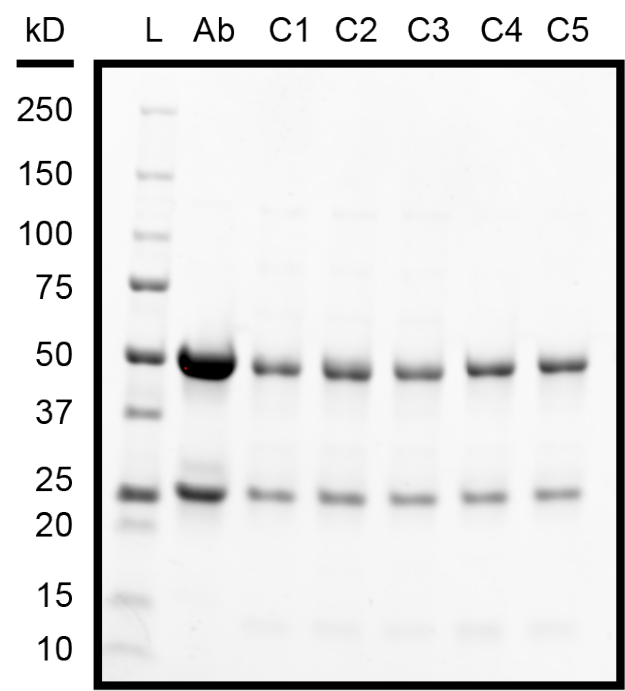

C

(+) TCO-PEG5K
$\mathrm{L} \quad \mathrm{Ab} \quad \mathrm{C} 1 \mathrm{C} 2 \mathrm{C} 3 \mathrm{C} 4 \mathrm{C} 5$
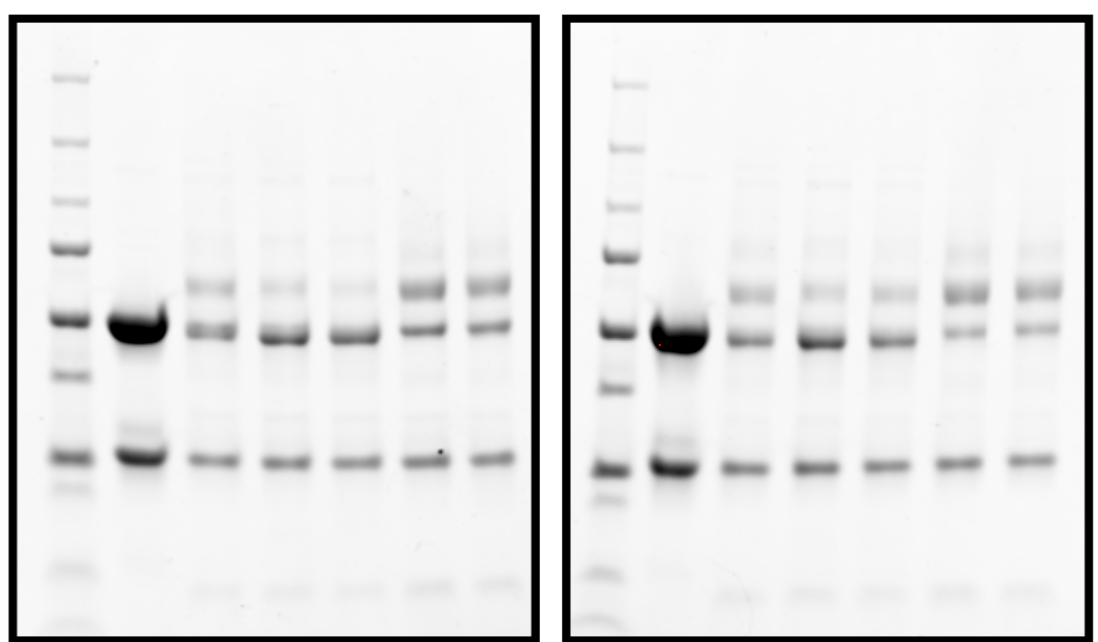

Supplementary Figure S29. SDS-PAGE analysis of conjugation efficiency. A) Linker-modified trastuzumab, B) Linker-modified trastuzumab reacted with DBCO-PEG5K, C) Linker-modified trastuzumab reacted with TCO-PEG5K.

Quantification of Electrophoresis Analysis of Linker Conjugation Efficiency

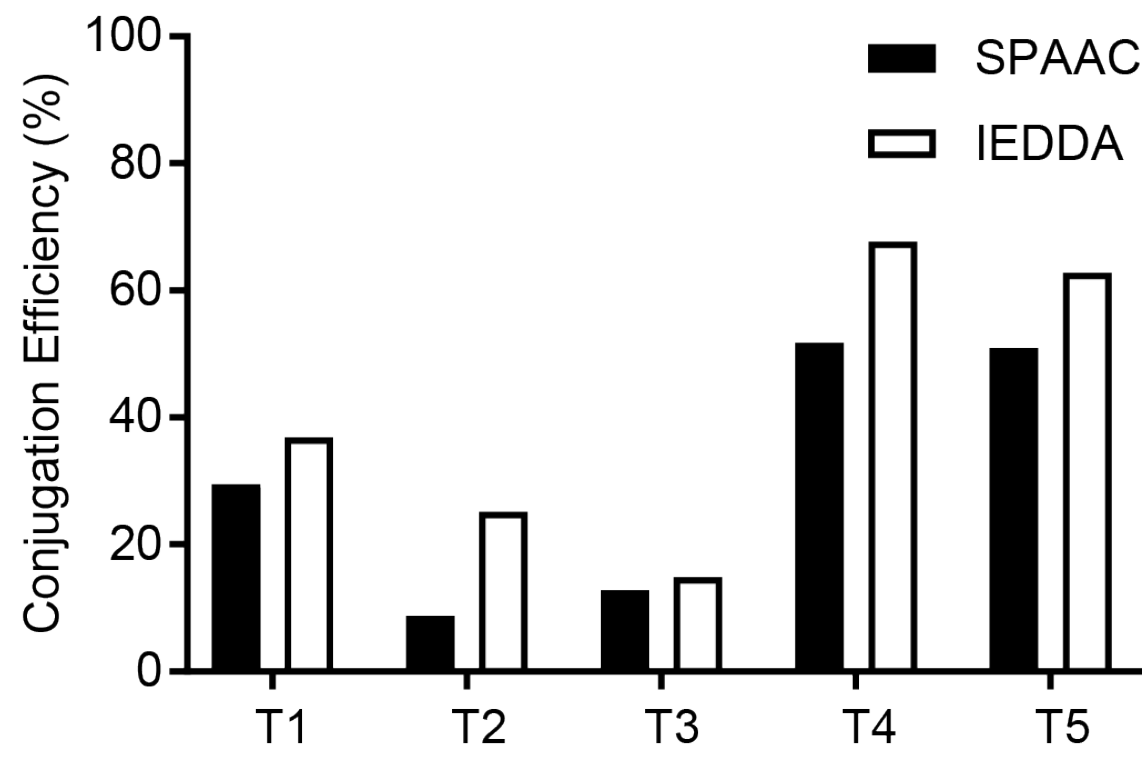

Supplementary Figure S30. Quantification of relative band intensity from SDS-PAGE analysis of linker conjugation efficiency. 


\section{Characterization of Conjugate T5 and Antibody-drug Conjugates}

\section{Large Scale Purification of Conjugate T5}

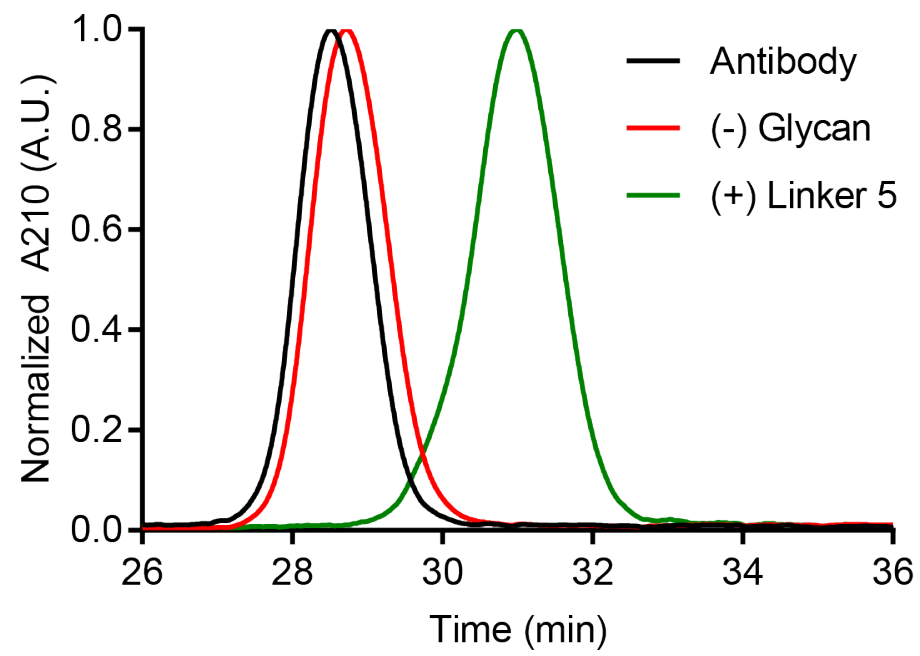

Supplementary Figure S31. HIC analysis of conjugate T5 purity.

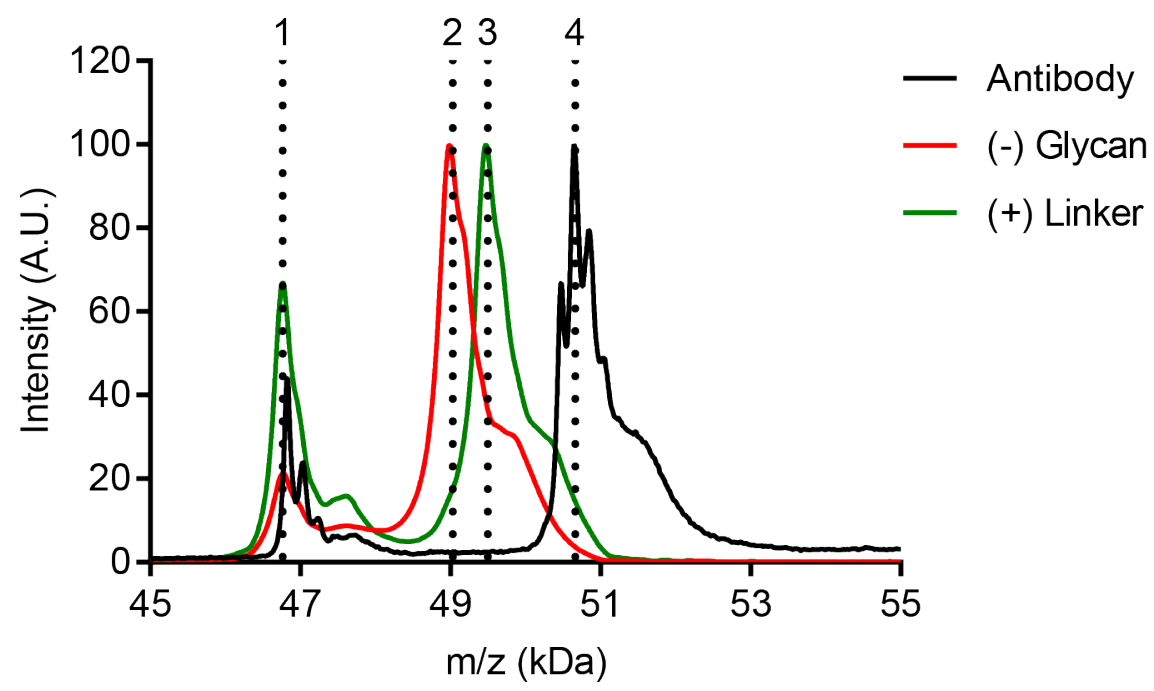

Supplementary Figure S32. MALDI-MS analysis of conjugate T5 molecular weight. Conjugate was reduced before analysis to confirm attachment of linker 5 to the heavy chain of the antibody. A double mass (1) of the light chain was observed at $46,792 \mathrm{Da}$. The heavy chain of the untreated antibody (4) was observed at 50,651 Da. Upon treatment with PNGase F (2), the aglycosylated heavy chain was observed at 49,021 Da, consistent with loss of a 1,630 Da consistent with removal of the glycan at position 297. Upon treatment with MTG in the presence of linker 5 (3), the linker-modified heavy chain was observed at 49,502 Da, consistent with one addition of linker 5 to the heavy chain. Observed difference: $481 \mathrm{Da}$, Expected difference: $500 \mathrm{Da}$. 
Gel Electrophoresis Analysis of Dual "Click" Modification<smiles>CCCC(=O)NCCOCCOCCN(CCOCCOCCN)C(=O)Cc1ccc(-c2nnc(C)nn2)cc1</smiles>
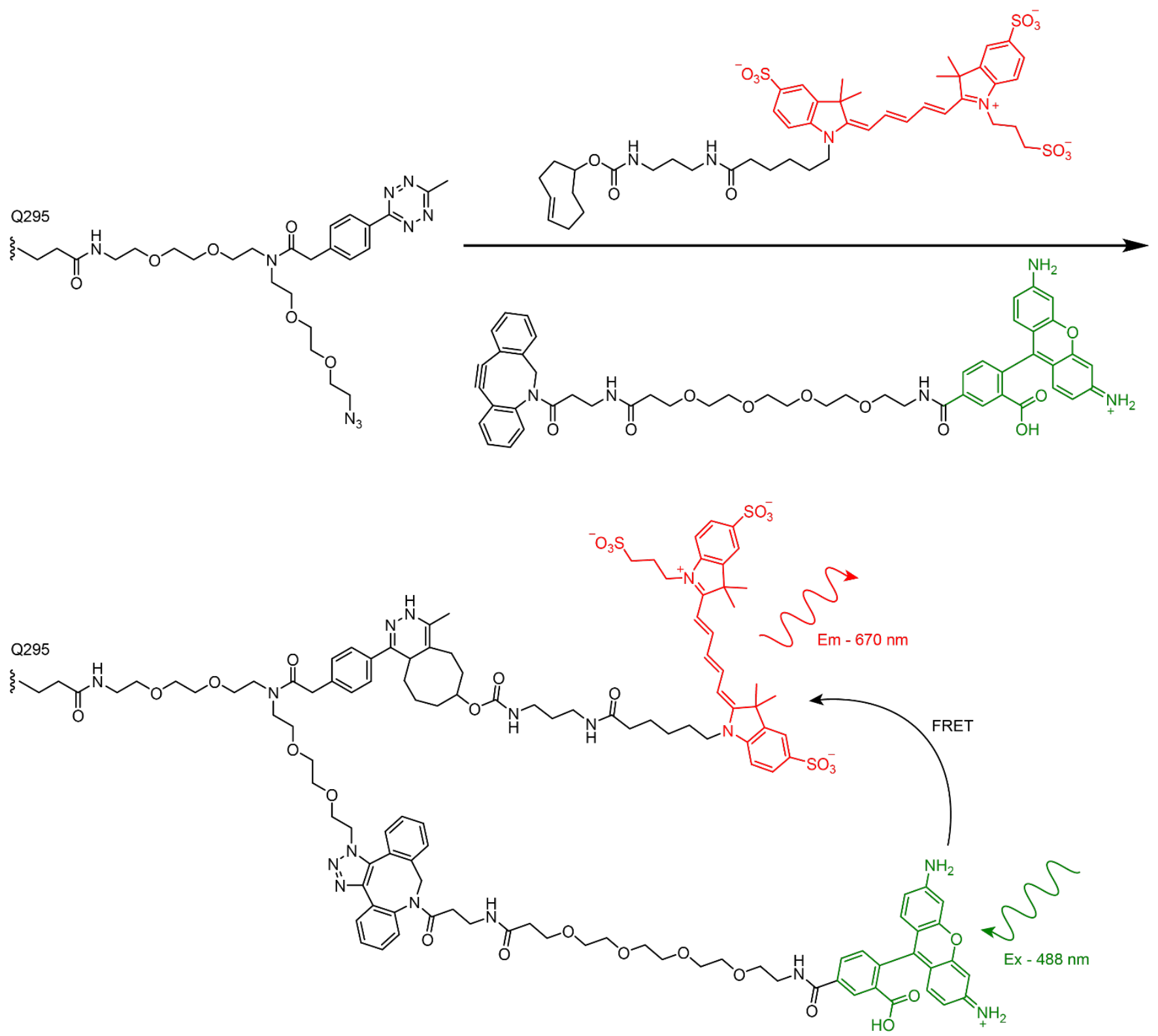

Supplementary Figure S33. Reaction scheme for dual "click" modification with FRET pair of fluorophores. 


\section{One-pot Synthesis of Antibody-drug Conjugates}
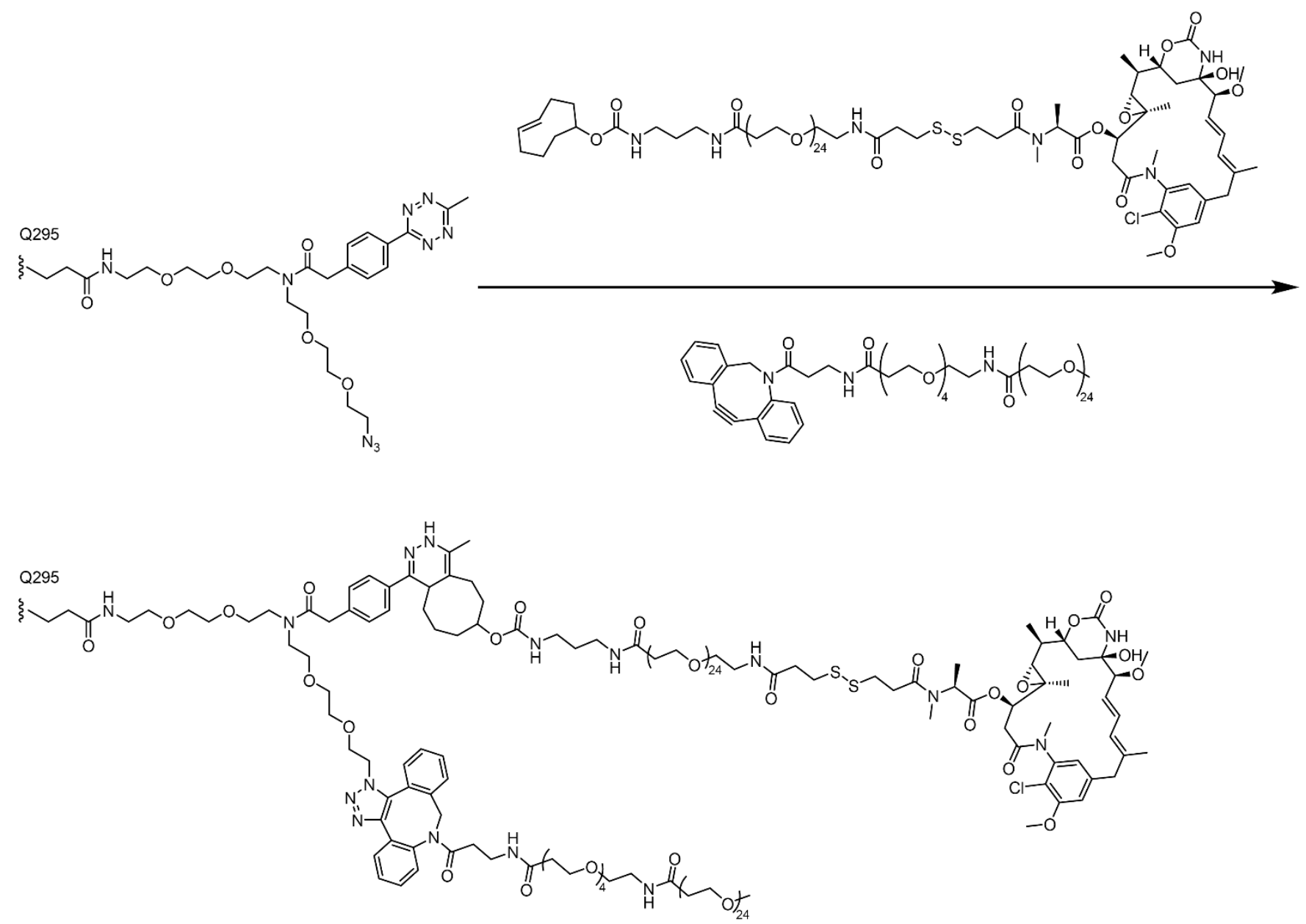

Supplementary Figure S34. Reaction scheme for dual "click" synthesis of antibody-drug conjugates. 

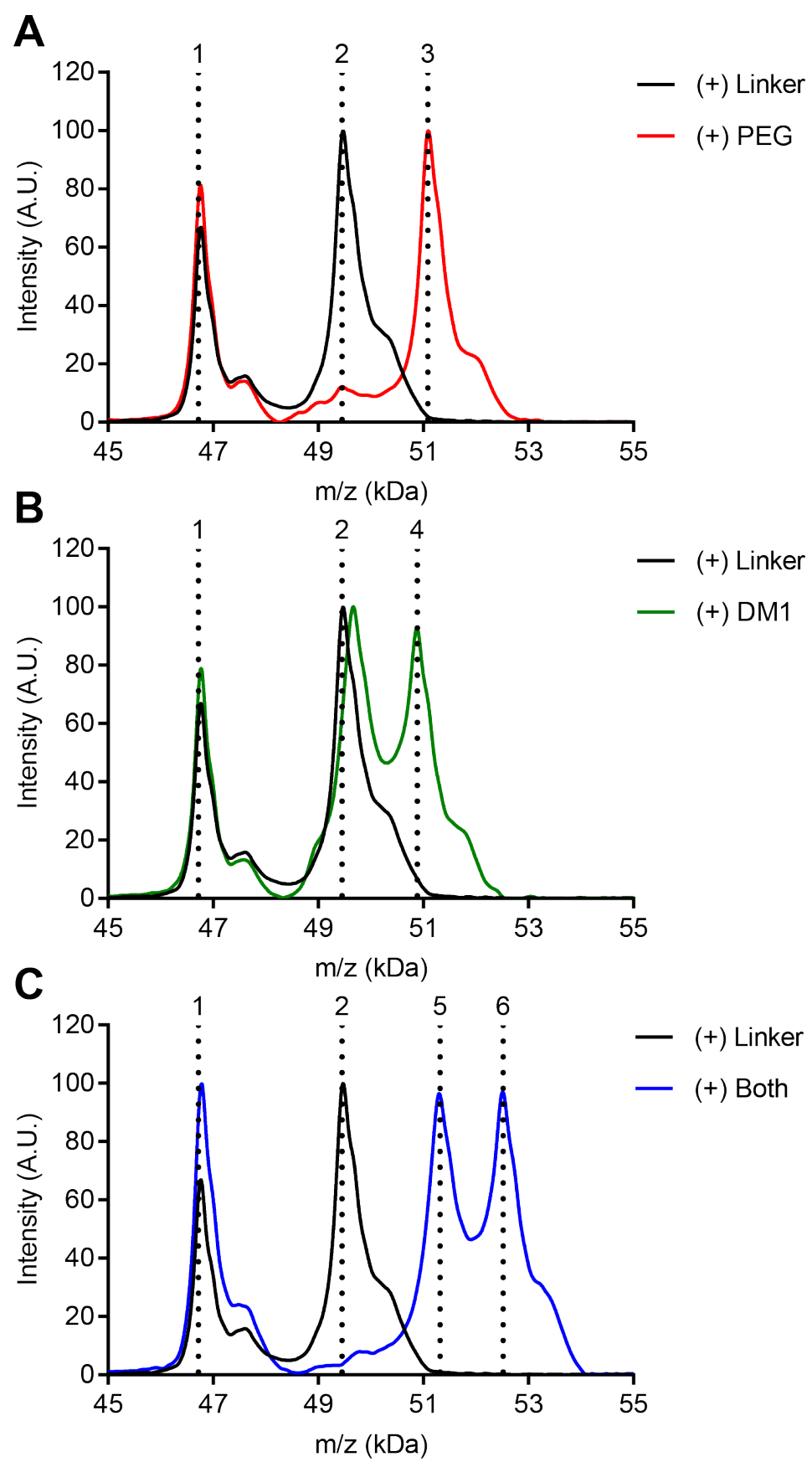

Supplementary Figure S35. MALDI-MS analysis of antibody-drug conjugate molecular weight. Conjugates were reduced before analysis to confirm attachment to the heavy chain of the antibody. A double mass (1) of the light chain was observed at 46,786 Da in all samples. The heavy chain of the linker 5-modified antibody (2) was observed at 49,502 Da. A) Upon addition of DBCO-PEG28, complete conversion was observed with the modified heavy chain (3) appearing at 51,124 Da; Observed difference: 1,622 Da, Expected difference: 1,622 Da. B) Upon addition of TCO-PEG24-DM1, partial conversion was observed with the modified heavy chain (4) appearing at 50,900 Da; Observed difference: 1,398 Da, Expected difference: 1,414 Da. C) Upon addition of both DBCO-PEG28 and TCOPEG24-DM1, partial conversion was observed. The first product (5) appeared at 51,331 Da corresponding to addition of DBCO-PEG28 (observed difference: $1829 \mathrm{Da}$, expected difference: 1622 $\mathrm{Da}$ ). The second product (6) appeared at $52,536 \mathrm{Da}$ corresponding to addition of both DBCO-PEG28 and TCO-PEG24-DM1 (observed difference 3,034 Da, expected difference: 3,036). 
In Vitro Potency of Antibody-drug Conjugates
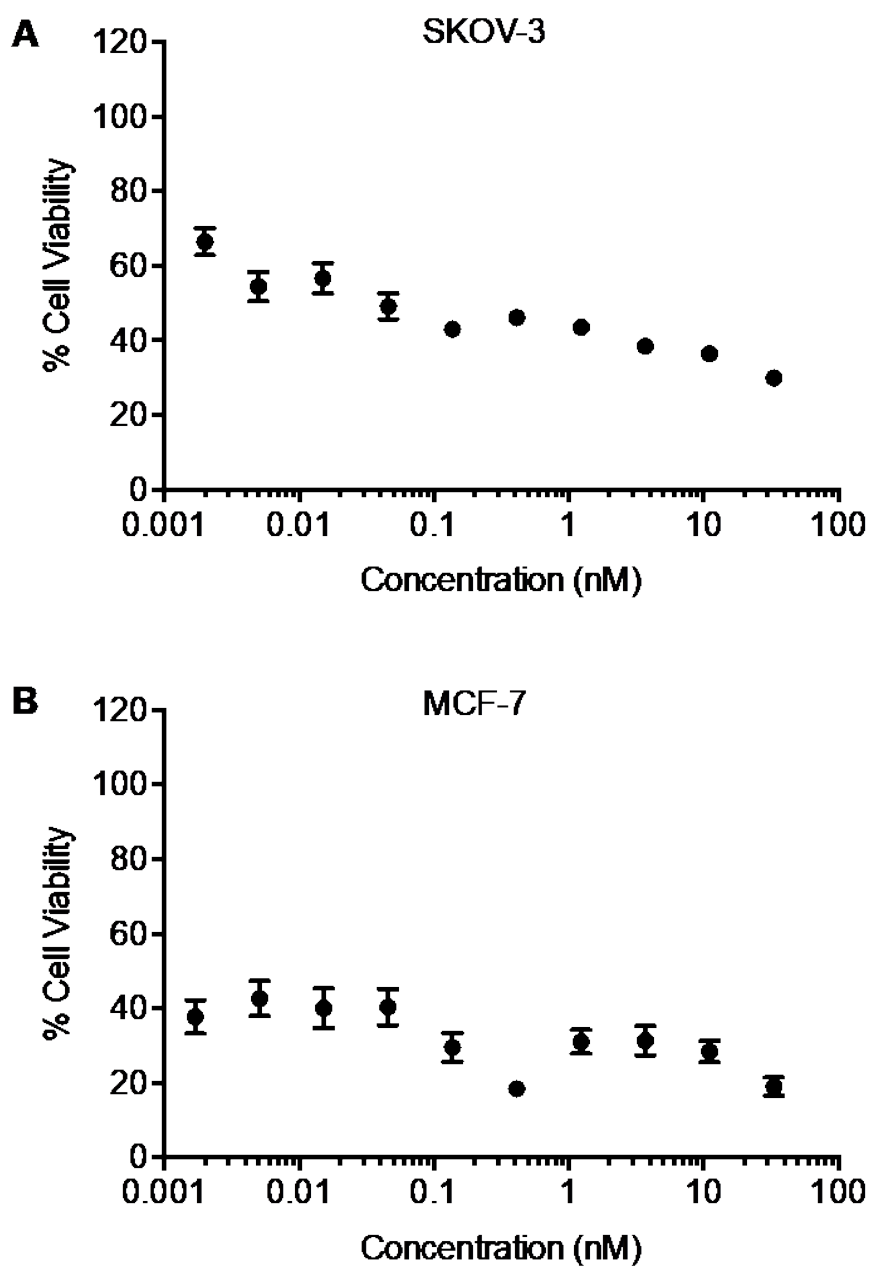

Supplementary Figure S36. In vitro potency of DM1-S-Me (drug alone) on A) SKOV-3 and B) MCF7 cells. 


\section{References}

(1) Gundersen, M. T., Keillor, J. W., and Pelletier, J. N. (2013) Microbial transglutaminase displays broad acyl-acceptor substrate specificity. Appl Microbiol Biotechnol 98, 219-230.

(2) Schindelin, J., Arganda-Carreras, I., Frise, E., Kaynig, V., Longair, M., Pietzsch, T., Preibisch, S., Rueden, C., Saalfeld, S., Schmid, B., et al. (2012) Fiji: an open-source platform for biological-image analysis. Nat Methods 9, 676-682. 